\title{
ELECCIONES GENERALES DEL 6 DE JUNIO DE 1993. LA CAMPAÑA DE LOS PARTIDOS NACIONALISTAS VASCOS
}

\author{
Ignacio María Beobide Ezpeleta \\ Universidad de Deusto-Bilbao
}

\section{Introducción}

El 6 de junio de 1993 se celebraron por sexta vez Elecciones Generales a Cortes. Las anteriores habían tenido lugar los años 1977, 1979, 1982, 1986 y 1989.

En el País Vasco junto a los Partidos de ámbito general participaron activamente tanto en la precampaña como en la campaña electoral el Partido Nacionalista Vasco, la coalición Eusko Alkartasuna-Euskal Ezkerra y Herri Batasuna.

En este trabajo se trata de analizar desde un punto de vista ideológico, propio de la Ciencia Política, las campañas de los Partidos nacionalistas, dejando de lado la larga pre-campaña y los demás Partidos Políticos, si bien éstos últimos serán tenidos en cuenta por constituir parte imprescindible de la campaña de aquéllos.

La fuente de análisis es la prensa diaria y, en concreto, los siguientes periódicos, utilizados en sus ediciones para Bizkaia o el País Vasco en su caso: El Correo Español-El Pueblo Vasco, Deia, Egin, El Mundo del País Vasco y El País. La cuantificación se ha hecho siguiendo los datos ofrecidos por El Correo por razones de uniformidad.

Este análisis cualitativo y cuantitativo se suma a otros ya publicados con el mismo objetivo de servir de base para un estudio general ideológico del nacionalismo vasco, a los que me remito para todo lo relativo a cuestiones metodológicas ${ }^{1}$.

\footnotetext{
1 Ver mis trabajos: Identificación ideológica de los partidos políticos en Euskadi, Revista Estudios de Deusto, enero-junio 1984, Bilbao, pp. 9-167; Elecciones Autonómicas de Euzkadi de 1984: Identificación ideológica de los partidos políticos, Revista Estudios de Deusto, julio-diciembre 1985, Bilbao, pp. 289-430; Nacionalismo en tiempo de elecciones, Revista Es-
} 
El trabajo presenta por separado cada campaña, distinguiendo en cada una de ellas los siguientes puntos:

1. Los datos básicos, expresados de forma cuantitativa.

2. La definición ideológica o imagen de Partido, elaborada a través de tres apartados: Contenidos nacionalistas o nacionalismo en sentido estricto; contenidos programáticos no nacionalistas, que expresan otras adscripciones ideológicas; y, por último, cuestiones de estrategia, de praxis política o, simplemente, de Gobierno; y

3. La actitud ante los demás Partidos o coaliciones participantes en la campaña.

El análisis revela la existencia de dos factores, uno circunstancial y otro permanente o estructural, que decidieron la campaña. El primero fue la expectativa creada por las encuestas de orientación de voto, que no daban a ningún Partido la victoria por mayoría absoluta. Esto hizo que una cuestión de praxis o estrategia política, la formación del Gobierno central, y, por añadidura, la cuestión de las coaliciones de Gobierno tanto central como autonómico, pasará a ser el principal tema de la campaña en aquellos Partidos como el PNV y EA-EUE, que se autodefinen por su voluntad y responsabilidad de gobierno. Esto es manifiesto, si se tienen en cuenta no sólo los datos, que expresamente se califican de «cuestiones de estrategia política», sino, también, las críticas a los Partidos Políticos.

Este factor aludido, si bien afectó a la campaña, lo hizo de una manera superficial, pues sólo incidió en alterar la importancia cuantitativa de los distintos contenidos, pero no afectó cualitativamente a la misma.

El factor determinante de las tres campañas se sitúa en la forma de entender e interpretar la relación entre la estructura social del País Vasco y el nacionalismo. Las campañas reflejan diferentes modos de comprender esta relación y, por consiguiente, valoraciones distintas de la integración, solidez e interrelación de los componentes de la sociedad vasca y de la capacidad operativa de la ideología y movimiento nacionalistas en su transformación.

PNV y EA-EUE interpretan la estructura social del País Vasco, y en consecuencia del electorado, fuertemente integrada en torno a valores sociales, económicos y culturales, sin olvidar elementos políticos, que están constituidos de manera previa y al margen del nacionalismo político y cultural vasco, aunque existan cada vez más aspectos sociales de signo nacionalista creados desde el poder de las instituciones autonómicas. No

tudios de Deusto, julio-diciembre 1991, Bilbao, pp. 387-488; Nacionalismo vasco: Nación y poder, Revista Estudios de Deusto, enero-junio 1993, Bilbao, pp. 9-98. 
hace falta destacar ahora, por ejemplo, el carácter dependiente de su economía. A semejante sociedad corresponde, lógicamente, un electorado dividido y variado, al que, por añadidura se le ofrecen tres alternativas nacionalistas.

Estos factores impiden realizar una campaña de signo netamente nacionalista. Se invoca el nacionalismo y se recurre a elementos míticos nacionalistas, pero únicamente como forma de legitimación de la petición del voto en determinados ámbitos políticos. Una campaña así es, en principio, socialmente realista, aunque, después, se deforme por el recurso a exagerar la capacidad de acción de los propios Partidos, lo cual es un recurso común de todo Partido y movimiento político y no político, que pretende atraer adhesiones mediante la construcción de una imagen de grandiosidad y eficacia del propio movimiento.

Las campañas del PNV y EA-EUE, especialmente la del primero, se orientan a conseguir el máximo de participación posible en el poder de las instituciones políticas y, mediante él, en las sociales. Para ello hay que contar con un electorado nacionalista y no nacionalista y, todavía más, con una estructura social, sobre todo en materia económica, que no permite de momento, a pesar de la profunda crisis, un nacionalismo económico.

Tales campañas se desarrollan con criterios funcionales para los fines previstos y, por ello, son moderadas y apenas nacionalistas.

En un tipo de sociedad como la vasca parece que los llamados Partidos nacionalistas moderados son conscientes de que la ideología nacionalista no es un instrumento general y universal de aglutinamiento y de integración social y, como consecuencia, de unidad y cohesión política. Deberían producirse cambios sociales significativos para que el nacionalismo pudiese cumplir el papel, que históricamente ha jugado y que en la actualidad está cumpliendo, más negativa que positivamente por negligencia de las organizaciones internacionales y de los grandes Estados, en los países del Este y Centro de Europa.

La interpretación, por el contrario, dogmática y abstracta del nacionalismo conduce a una utilización del mismo de signo atemporal y ajena a la realidad social. El olvido de que el nacionalismo es operativo sólo en determinadas circunstancias sociales conduce a Herri Batasuna a una praxis en la que los mitos y contenidos nacionalistas son interpretados y utilizados como una variable absolutamente independiente y tan poderosa, que es capaz de movilizar, integrar y aglutinar ex novo una sociedad cuyas estructuras básicas, incluidas las políticas, no responden a las tesis nacionalistas.

La campaña de Herri Batasuna es un fiel reflejo y aplicación de una interpretación falsa tanto de la sociedad vasca como de la operatividad 
del mito del nacionalismo. La campaña es esencialmente nacionalista, pero social y políticamente inoperante.

Se trata de tres campañas ideológicamente muy pobres, que, en algunos momentos, tienen aspectos esperpénticos. Toda ella, vista en su conjunto, es una fiel prueba de que los Partidos nacionalistas carecen de visión y de política de Estado, limitando ésta a una fácil crítica de la política gubernamental y a una continua reivindicación de derechos y competencias.

\section{La campaña del Partido Nacionalista Vasco}

\section{Datos básicos}

No hubo mucha diferencia en el caso del PNV entre la atención prestada a destacar la definición e imagen de Partido y la dedicada a criticar a los demás Partidos contendientes en las Elecciones. La primera ocupó un $51,35 \%$ de espacio y la segunda un $48,64 \%$. Fue un resultado parecido al de la coalición de Herri Batasuna.

En tres apartados, tal como se decía en la introducción, se concentran los diversos contenidos del primer aspecto de la campaña, la definición e imagen del Partido. El primero, el de la Ideología nacionalista, fue muy poco relevante, tanto por la cantidad, únicamente el 7,58\%, como por la cualidad, ya que los contenidos de autogobierno, Estatuto de Autonomía y autodeterminación,- - habría que exceptuar a esta última-, no son esencialmente cuestiones nacionalistas, aunque históricamente hayan podido constituir de manera predominante el núcleo de las reivindicaciones nacionalistas, marcando diferencias notables en este aspecto con otros movimientos, Partidos e ideologías políticas.

El segundo apartado, el relativo al desarrollo de cuestiones programáticas ajenas a la ideología nacionalista en sí misma considerada, tuvo un mayor espacio, 40,35\%, destacando la atención prestada a la reinserción y la pacificación, el 13,49\% del total de la imagen de partido. Otras materias tratadas aquí fueron la política económica e industrial, el Banco Público Vasco, la incorporación de Treviño a Euskadi, la droga, la corrupción, el carácter democrático cristiano del PNV, el europeísmo y alguna breve referencia a la insumisión. A todo ello hay que sumar lo que se podría llamar mera lectura de bastantes de los llamados cien puntos, que contenía el programa del PNV. Si se exceptúa la atención prestada a la reinserción y a la política económica e industrial, todos los demás puntos resultan inapreciables e insignificantes en el cómputo general de la campaña del PNV. 
El tercer apartado, que recoge cuestiones estratégicas y de gobierno, ocupó más de la mitad de esta primera parte, el 52\%, destacando muy especialmente la atención prestada a la futura coalición de Gobierno, que las encuestas electorales daban por segura, y la posible participación en ella del Partido Nacionalista. Casi el 38\% de la imagen se construyó en torno al problema de la gobernabilidad del País y a la postura del Partido Nacionalista ante él. Esto quiere decir en valores relativos al total de campaña que una de cada cinco palabras se dijo sobre ese motivo. La denuncia de la bipolarización de la campaña, cuestión íntimamente unida a la anterior, y la importancia de la presencia del Grupo Vasco en el Congreso completaron este apartado con el $10,41 \%$ y el $3,72 \%$ respectivamente.

El segundo aspecto de la campaña, el de la crítica a los Partidos Políticos, dió los siguientes resultados porcentuales: Partido Popular, 43\%; Partido Socialista Obrero Español-Euskadiko Eskerra, 33,24\%; Herri Batasuna, 14,78\%; Unidad Alavesa, 7,59\% y, por último, Euzko Alkartasuna, $1,35 \%$.

Los protagonistas de la campaña fueron Arzalluz con el 37,96\% de participación y Anasagasti con el 19,49\%, siguiendo a continuación Atutxa, Zubia, Ansola, Ardanza, Egibar, Allende, González Txabarri y Olabarría, con porcentajes que van desde el casi $10 \%$ de Atutxa hasta cantidades inapreciables. Destaca la escasa participación del Lehendakari Ardanza, aunque intervino en los actos principales.

\section{Desarrollo de la campaña}

A) La definición e imagen de Partido

1. La ideología nacionalista

La utilización de la autodeterminación, concepto tan recurrido en general por el nacionalismo, fue utilizado en el contexto de la actitud del Partido Nacionalista ante la formación del gobierno de coalición posterior a las Elecciones y, más en concreto, en respuesta a las acusaciones de que un pacto de gobierno con el PNV supondría la venta de España al nacionalismo por las exigencias, que éste impondría. «Mi partido - dijo Arzalluz - no va a plantear ninguna cuestión de autodeterminación en estos próximos cuatro años. Plantearemos que tiene que concluir la implantación del Estatuto de Autonomía, que es una ley»².

2 El Correo, 28-V-93 (30). La numeración en paréntesis o, simplemente, la última cifra indica la página. Aunque no se indique en las notas, casi todos los contenidos generales (v.g. mítines) se encuentran confirmados por los demás periódicos, bien del mismo día o bien del 
La razón inmediata, que está detrás de semejantes palabras, que se repetirán en ocasiones distintas, es la de no crear obstáculos a una posible participación en el Gobierno central. Pero la razón de fondo parece ser que la autodeterminación no es un instrumento positivo para los fines generales del PNV. Como su negación radical afectaría a la esencia del nacionalismo y, por ello, restaría el apoyo de ciertos sectores básicos, se reconoce su validez general o en abstracto y se niega su aplicación o utilización en un tiempo limitado, con lo cual se crea un lazo de unión con un electorado más amplio. Con ello se salvan los principios nacionalistas y se intenta seguir, a la vez, una estrategia política eficaz. Dicho con otras palabras, se salva la legitimidad nacionalista a la vez que se hace posibilismo político. Es decir, se alimenta la creencia, que fundamenta la cohesión del grupo o partido, por un lado, y, por el otro, se crean las condiciones pragmáticas de acceso al poder.

En otro contexto y con otras motivaciones se defiende también la marginación temporal de la autodeterminación. En este caso la razón última es económica. El paro afectaba a la juventud y existía el temor a perder más puestos de trabajo. En tales circunstancias, «los debates de realismo mágico, aunque son importantes —manifestó Iñaki Anasagasti-, porque no renunciamos a nuestros principios, no son urgentes. Hicimos lo que teníamos que hacer, planteamos el debate (sobre la autodeterminación) en el Parlamento vasco y la sociedad conoce nuestras opiniones al respecto. Nuestras prioridades van por el fortalecimiento de la sociedad vasca desde el punto de vista económico y desde el punto de vista del autogobierno» ${ }^{3}$. Para ello había que estar donde se jugaba el interés de Euskadi, gustase o no. «Y mientras estemos en el Estado español hay que estar en sus órganos de decisión». Esto quería decir en opinión de Arzalluz que, aunque el PNV estaba formado por nacionalistas vascos, defensores del derecho de autodeterminación del pueblo vasco para, en consecuencia, estar en el Estado español o fuera de él, sólo o acompañado, había que distinguir el tiempo adecuado para cada cosa. El criterio del momento adecuado para la autodeterminación era el del éxito, el de la victoria de la misma. Jamás el PNV plantearía una cuestión sin la seguridad de que iba a ganar. Avalaban este planteamiento el conjunto de éxitos obte-

siguiente. Las diferencias no suelen ser cualitativas, sino cuantitativas, es decir, de espacio. $E l$ País da poca información. Las entrevistas se salen de este criterio, pero no añaden diferencias de fondo.

3 El Correo 31-V-93 (22). Ver, también Deia 39-V-93, donde Arzalluz afirma que el PNV no va a plantear «ningún referéndum autodeterminante, aunque defendemos la autodeterminación». Hablar de ella en la campaña era hacer demagogia; lo importante era tratar los problemas reales del pueblo vasco, entre los que se destacaba la situación económica. 
nidos por el PNV en los últimos años desde la amnistía y el Estatuto hasta el Concierto, la Televisión, la ertzaintza y el euskera. Todo lo contrario del fracaso permanente de la estrategia de ETA y Herri Batasuna ${ }^{4}$.

Una respuesta ininteligible sobre la autodeterminación fue la que dio Egibar al ser preguntado sobre la misma en la mesa redonda organizada por Egin-Irratia al decir: «La Constitución española consagra un modelo de Estado que no nos gusta, que reprobamos en su día y que intelectualmente seguimos reprobando. En su día nosotros argumentamos que la soberanía reside en los pueblos que integran esa forma política denominada Estado español, y no fue aceptada esta tesis. Pero somos posibilistas y pragmáticos y nos presentamos con un programa electoral que ponemos sobre la mesa para llegar a acuerdos.Si no se acepta lo que puede significar una opción como la del PNV, estaríamos en una situación de plantear un conflicto al Estado» ${ }^{5}$.

Este planteamiento es absolutamente contrario al que expuso Herri Batasuna en su campaña y los dos deben ser interpretados desde la óptica de la función, que cumplen los mitos en el enmascaramiento y ficción de la realidad social. Por lo que respecta al caso del PNV, Anasagasti repite el mismo esquema y las mismas argumentaciones de fondo que Arzalluz: legitimidad y poder, antes político y ahora económico. Pero, en cualquier caso, el PNV era un partido «cuyo inicio y final es Euskadi, frente a otras formaciones que consideran que Euskadi es un apeadero» ${ }^{6}$.

Las declaraciones de Joseba Zubia sobre la autonomía vasca también se dijeron en el contexto de la posible llamada al PNV para formar un Gobierno de coalición. En tal caso el PNV no exigiría privilegios, sino que se respetase total y absolutamente el Estatuto de Guernica. Por respeto debía entenderse la transferencia de las 55 materias incluidas en el llamado Informe Zubia, así como otras cuestiones tales como la garantía de que las leyes posteriores no habrían de recortar las competencias transferidas, la modificación de las leyes básicas que ya habían reducido competencias y el abandono de la práctica de recuperar competencias basándose en los acuerdos con la Comunidad Europea. Por otra parte - ahora se hablaba en nombre del Gobierno autónomo-, se reclamaría una coordinación estatal basada en la planificación por el Gobierno central y en la ejecución por las autonomías, además de la reforma del Senado, Tribunal Constitucional, Consejo Económico y Social y Banco de España, que diese más participación a las Comunidades Autónomas. Si el proceso de transferencias estaba detenido desde hacia seis años, no era, declaró Zubia, por vo-

\footnotetext{
4 Deia 2-VI-93 (5)

5 Egin 28-V-93 (14).

6 Palabras de Anasagasti en Egin 22-V-93 (4).
} 
luntad del Gobierno Vasco o por supuesta política de victimismo del PNV. Había «escasa o nula sensibilidad autonómica» en los partidos de ámbito estatal, lo que podría explicar que el Estado de las Autonomías fuera el gran ausente del debate electoral ${ }^{7}$.

El autogobierno fue defendido por Ardanza como instrumento de bienestar, de prosperidad y de modernización de Euskadi. Elementos del autogobierno eran, además del Estatuto - sobre el que Anasagasti dijo que no era de recibo que no se cumpliese ${ }^{8}$-, el Cocierto Económico, la transferencia del INEM y la creación del Banco Público Vasco9. La identificación entre desarrollo del Estatuto y autogobierno aparece, también, en manifestaciones de Joseba Zubia, quien, además, consideraba imprescindible un cambio total en la forma del Estado para recuperar el espíritu del Estado de las autonomías ${ }^{10}$, ya que las nuevas orientaciones -añadió el viceconsejero Javier Balza- de federalismo corporativo o de administración única eran contradictorias con el modelo definido en la Constitución y en los Estatutos ${ }^{11}$.

En este orden de cosas, Arzalluz opinaba en unas declaraciones realizadas al periódico checo «Hospodarske Noviny» que el nacionalismo no sería un factor desintegrador en Europa, ya que «los países miembros de la Comunidad Europea están ya demasiado entrelazados entre sí política y económicamente». La solución a los movimientos nacionales estaba en la integración de Europa por regiones. El proceso de creación de la C.E. llevaba al fin de los Estados soberanos. «Desde este punto de vista, es lógico que el PNV pretenda para el País Vasco su entrada directa en Europa sin la intermediación del centro, cuyo protagonismo en este caso desaparece». Arzalluz defendía a la vez que cada nación tenía derecho a decidir sus propios destinos y que la fragmentación de los Estados del Centro y Este de Europa se debía a «la desintegración de los regímenes comunistas y a la posibilidad de construir algo nuevo» ${ }^{12}$.

\section{Cuestiones programáticas}

Entre los temas desarrollados en esta sección, que ocupó el 40,35\% de la imagen, identificación o definición del partido, destaca el punto de la paz y del terrorismo. El PNV aceptó la iniciativa de la Plataforma Cívica

\footnotetext{
7 El Correo 4-VI-93 (30).

8 Deia $23-\mathrm{V}-93$ (4).

9 Deia $24-\mathrm{V}-93$ (3).

10 Deia 4-VI-93 (3).

11 Ibídem.

12 Deia 5-VI-93 (5).
} 
por la Paz-Bakea Orain —aunque no firmó el manifiesto propuesto-, que trataba de evitar que la cuestión de la violencia se convirtiese durante la campaña en arma arrojadiza de un Partido contra otro. El documento, en que se plasmó tal iniciativa, expresaba el compromiso de los Partidos firmantes de «no emplazar al rival político a la realización de promesas electoralistas que después resultan comprometedoras y de no entrar en dinámicas maximalistas que prefiguren la solución al problema y fomenten la intransigencia social», además de alentar e impulsar entre sus militantes y votantes la participación en la pacificación y reconciliación y de no transmitir la idea de que el problema de la violencia estaba casi resuelto $^{13}$. El PNV se sumó al proyecto, tal como también lo hizo Eusko Alkartasuna-EUE, con un texto propio, en el que manifestó que «el objetivo de una paz estable y duradera en Euskadi no debe ser utilizado como argumento de instrumentalización política» ${ }^{14}$.

No obstante este compromiso, el PNV y el Partido Popular fueron acusados tácitamente de no respetar lo que habían prometido por su polémica electoral sobre la reinserción de lo presos de ETA ${ }^{15}$.

Sobre esta última cuestión J.M. Atutxa defendió la tesis totalmente contraria a la que habia expresado en Vitoria José María Aznar en una conferencia de prensa. El Consejero de Interior del Gobierno Vasco se mostró partidario de la reinserción y rehabilitación de etarras, incluso de aquéllos, que tenían delitos de sangre. «Prefiero - dijo expresamenteque una persona de las características de Iñaki de Juana Chaos, con 2.735 años de condena a sus espaldas y que estará encarcelado treinta años, salga a los ocho o diez años totalmente reconducido, rehabilitado y reinsertado, a que salga dentro de treinta años mirando a los cuatro costados y pretendiendo hacerse con una pistola para liarse a tiros nuevamente. Creo que es la meta que debemos conseguir y a la que debemos llegar» ${ }^{16}$. Para Atutxa resultaba difícil distinguir entre los delitos, que exigían el cumplimiento absoluto de las penas, y los que no. En cualquier caso y «queriendo ser respetuoso con el sufrimiento que todo ello ha supuesto para todas las víctimas del terrorismo y sus familiares, soy de los que piensan que hay que reconducir esta situación y reinsertar a estas personas. Pero es muy difícil poner el listón en los delitos de sangre para cumplimiento total de penas y hacer abstracción de otras personas

13 El Correo 22-V-93 (12).

14 Ibídem. Ver, también, Deia 29-V-93 (3).

15 Ibídem.

16 El Correo 21-V-93 (12). Posteriormente Atutxa manifestó que un triunfo del Partido Popular agravaría las condiciones para los miembros de ETA y «los compinches que les alientan» (Deia 3-VI-93, 3). 
que para mí son tanto o más responsables que las mismas ejecutoras directas» ${ }^{17}$.

Atutxa era de la opinión de que la mayoría de los reclusos etarras estaba a favor del abandono de la lucha armada y de la misma organización $\mathrm{y}$, por supuesto, de su reinserción en la sociedad, pero sus dirigentes no se lo permitían. «Son — dijo- verdaderoe rehenes de la propia banda, no rehenes del Estado, como en muchas ocasiones dice el colectivo KAS» ${ }^{18}$.

Arzalluz también insistió en la reinserción de presos con delitos de sangre, pues «éso es lo que dice el Pacto de Ajuria Enea en su punto noveno; aquí no estamos inventando algo» ${ }^{19}$. Era política clara del PNV la pretensión de que la violencia no terminase con una victoria policial, porque dejarían odios suficientes para que volviese a resurgir. En materia de reinserción el PNV se atenía a lo firmado en el Pacto de Ajuria Enea y a lo escrito en su programa basado en los principios de generosidad, diálogo y justicia ${ }^{20}$.

A pesar de las recomendaciones conocidas de no crear falsas expectativas sobre el fin de ETA, Anasagasti respondió al entrevistador, que preguntó si tenían datos objetivos para afirmar que el año 1994 sería decisivo para acabar con ETA, cosa que venía diciendo el PNV, que tales datos eran el desgaste de ETA, lo sucedido en 1992 y 1993 y el «discurso de la propia sociedad» que cada día marginaba más ETA ${ }^{21}$. De manera más concreta ya había dicho que estaba próximo el fin de la violencia basándose en las siguientes razones: La presión interna en las cárceles; la presión de la sociedad; los éxitos policiales y la colaboración con Francia $^{22}$. Lo mismo hizo Atutxa al afirmar que en la siguiente legislatura se podría «brindar por el fin del terrorismo» ${ }^{23}$.

La inactividad de ETA durante la campaña constituía un parón totalmente estudiado, que trataba de evitar reacciones sociales contrarias. Este era el parecer de Atutxa, que, por otra parte, destacó el buen trabajo realizado por su Partido en materia de seguridad ciudadana durante la anterior legislatura, lo que exigía, para continuar esa labor, «un grupo fuerte y sólido, un grupo que se haya diferenciado por su seriedad, constancia y sinceridad en defensa de la ciudadanía vasca» ${ }^{24}$.

\section{Ibídem.}

18 Ibídem.

19 El Correo 27-V-93 (34)

20 Deia 28-V-93 (6). Ver, también, Deia 29-V-93 (5).

${ }^{21}$ El Correo 31-V-93 (23). Sobre los temas generales de la campaña ver la entrevista a Anasagasti en Egin 27-V-93 (16 y 17).

22 Deia $28-\mathrm{V}-93$ (6).

${ }_{23}$ Deia $21-\mathrm{V}-93$ (7).

24 Deia 28-V-93 (6). 
Sobre el indulto a Amedo y Domínguez la postura dominante fue la de que no era el momento para tratar de semejante cuestión. Sin embargo, Atutxa expresamente manifestó que, si bien en este caso no procedía la reinserción, a Amedo debía dársele el mismo trato que a los presos etarras en los supuestos de que pidiese la reinserción y demostrara que estaba por la «labor de reconducir su vida» ${ }^{25}$. Anasagasti fue más exigente al decir que estaba dispuesto a apoyar la reinserción cuando acabasen todas las violencias. La reinserción o el indulto en aquellas circunstancias sería perjudicial para la democracia ${ }^{26}$. Arzalluz fue claro al considerar que no eran las circunstancias adecuadas para tratar el caso, pero se sumió en la duda al decir: «En este asunto hay tantas heridas de diferente origen que tampoco se puede descargar toda la ira o toda la benevolencia en torno a Amedo, ya que éstos son fenómenos de acción y reacción, y si es injusta la acción, injusta puede ser la reacción, como en este caso» ${ }^{27}$.

La política económica e industrial a seguir en el País Vasco - primera prioridad del PNV en unas futuras negociaciones ${ }^{28}$ - no podía basarse en un acto exclusivo para el País Vasco, tal como Aznar, según Arzalluz, habría propuesto en unas manifestaciones, sino en un compromiso global, que abarcase a toda España. «Si nosotros — dijo—vamos a llegar a un acuerdo con el señor Aznar no vamos a llegar a un acuerdo sobre Euskadi, vamos a llegar a un acuerdo sobre la política económica e industrial que afectará a todo el mundo. No vamos a pedir que llueva sólo para Euskadi, porque además es imposible» ${ }^{29}$. Por otra parte, el problema económico tenía tal prioridad que había que establecer el delito económico para combatir el fraude laboral, que cometían los que, estando inscritos en el INEM, seguían trabajando. El caso requería la intervención de los sindicatos para no defender al vago y al absentista, porque el daño, razón muy populista, ahora no iba contra la empresa, sino contra los propios compañeros ${ }^{30}$.

Lo primero que pensaba plantear el PNV en Madrid, si los resultados le eran favorables, era el problema de la regeneración industrial de

25 El Correo 21-V-93 (13).

26 El Correo 31-V-93 (23). Dentro de este apartado de nacionalismo hay un texto, que por ser único no tiene más relevancia que la de la pura anécdota, pero que, sin embargo, tiene todo el valor de una respuesta espontánea de conciencia. Se trata de la respuesta dada a la pregunta hecha a Anasagasti de si le importaría compartir candidatura con un gitano. Anasagasti respondió: «Si el gitano tiene salero, y no tiene problemas para ponerse la txapela, hablar euskera y respetar lo vasco, pues encantado de la vida» (El Correo 31-V-93, 23).

27 El Correo 21-V-93 (13).

28 Deia 2-VI-93 (5).

29 El Correo 22-V-93 (32). La reclamación de un desarrollo económico respetuoso con el medio ambiente aparece en Deia 4-VI-93 (5) y en Deia 5-VI-93 (5).

30 Ver El Correo 30-V-93 (40). 
Euskadi $^{31}$. Esto no impedía que, al final de la campaña y de acuerdo con la idea inicial de que el problema era general y no particular, el Consejero Larrea, para quien la salida de la crisis iba a ser mucho más complicada de lo que se había dicho, recomendase al Estado la aplicación de las mismas medidas fiscales, financieras y presupuestarias que el Gobierno Vasco ya venía aplicando. La ausencia en la campaña del fraude fiscal había sido un hecho y Larrea recordó las propuestas programáticas de su Partido para evitar el fraude, tales como el destino de más personal a las tareas de inspección y la promoción de una cultura fiscal, además de las ventajas que ofrecía el sistema tributario vasco en el control de la recaudación, en la lucha contra el fraude y en el compromiso del ciudadano ${ }^{32}$.

La responsabilidad de la crisis de ninguna manera era del PNV, ya que las instituciones vascas estaban haciendo el esfuerzo adeduado de inversiones para atraer otras inversiones. La culpa estaba en la violencia, en la «dejación industrial» del Gobierno socialista, en su obstrucción sistemática a las iniciativas industriales del PNV y en la imposibilidad de que los hombres del PNV pudiesen actuar en la empresa pública dada su ausencia de la misma. «Por eso nosotros — afirmó Anasagasti- predicamos la posibilidad de que la gran empresa pública dé entrada a las autoridades representativas de la comunidad. A veces se nos acusa de ser responsables de la crisis de Altos Hornos, siderúrgica, Naval..., pero la verdad es que nos parece una crítica tremendamente injusta» ${ }^{33}$.

Este punto era una de las cien propuestas que el PNV defendía en su programa y que, según los presentadores del mismo, integraban su aportación al debate electoral. Entre tales propuestas, que demostraban en opinión del PNV el carácter estatal de su programa, destacaban la reducción de los tipos del IRPF y del impuesto sobre Sociedades, la modificación del impuesto de Actividades Económicas, la contención del gasto de funcionamiento y personal de las Administraciones Públicas, la participación del Gobierno Vasco en la gestión del Banco de España y Argentaria, la culminación del desarrollo del Estatuto de Autonomía, un pacto social sobre el empleo, la reforma del INEM, la constitución de la figura del jurado, la reducción del período transitorio en materia de pesca, la actuación del Parlamento Europeo como auténtica cámara legislativa, la creación de la circunscripción electoral vasca para el Parlamento Europeo, relaciones directas de Euskadi con las instituciones comunita-

31 Deia 1-VI-93 (4).

32 Deia 5-VI-93 (5).

33 El Correo 31-V-93 (22) y Deia 31-VI-93 (4), donde aparece la política industrial propuesta por el PNV, que repite tópicos y lugares comunes sobre el tema. 
rias, la supresión del servicio militar obligatorio, la despenalización de la insumisión y la creación de un sistema europeo de defensa profesionalizado ${ }^{34}$.

Todo esto era parte de un programa, pero no fue la base de la campaña electoral, sino, como ya he indicado, objeto de una lectura rápida. Tampoco fue fundamento de la campaña el anuncio de que el PNV propondría en el Congreso aumentar la cooperación con los países del Tercer Mundo con medidas tales como la dedicación del 0,7 del PNB al desarrollo de tales países o la inclusión, entre las formas de Prestación Social sustitutoria, de la figura del cooperante y el reconocimiento de su cobertura por la Seguridad Social durante el período de trabajo en el Tercer Mundo o la desgravación fiscal por las cantidades donadas a organizaciones para el desarrollo o el establecimiento de incentivos para las personas de la tercera edad, que aportaran sus conocimientos y competencias a proyectos de cooperación ${ }^{35}$. El PNV insistió más en la defensa de los intereses vascos, reclamando competencias en materia de infraestructuras (puertos, aeropuertos, etc.), proponiendo la participación de los usuarios en algunas obras de infraestructura, defendiendo la unidad de gestión en materia de transporte público en las capitales de la CAV y solicitando la realización de las grandes obras pendientes ${ }^{36}$.

La aprobación del Banco Vasco ni era un golpe de efecto electoral ni un aviso para quienes querían pactar con el PNV. «... como era un tema muy maduro el Gobierno lo ha presentado ahora. Además, nosotros no lo hemos tomado como un órdago a la Administración central, simplemente estaba ahí y se ha aprobado ${ }^{37}$.

Tanto Ardanza como Arzalluz defendieron el Banco Público Vasco basándose en los acuerdos de coalición con el PSOE, en la ayuda que supondría para superar la crisis, en ser materia competencial compatible con el Estatuto y el Concierto Económico, en la experiencia de los länder alemanes y cantones suizos y en que había sido uno de los puntos del

34 Deia 21-V-93 (5). Ver, también, sobre la necesidad de los incentivos fiscales, en Deia 29-V-93 (3) las palabras de José Alberto Pradera. Sobre los mismos dijo Arzalluz que eran obra del PNV, pero que «luego vienen de Madrid con el hacha y dicen: éstos están creando aquí paraísos fiscales. Ni paraísos, ni historias. Si es tan bueno, hacerlo y si es malo, dejar que se hundan los vascos que os gusta tanto (sic)», en Deia 30-V-93 (5).

35 Deia $27-\mathrm{V}-93$ (5).

36 Deia 2-VI-93 (5).

37 El Correo 31-V-93 (23). Sobre el Banco Público Vasco y otras cuestiones como la defensa de los intereses de Araba por el PNV, críticas al Gobierno Socialista por su actitud centralizadora, pactos postelectorales y Unidad Alavesa, ver en Deia 30-V-93 (7) la entrevista a Emilio Olabarría. Ver, también, Deia 31-V-93 (3) y 5-VI-93 (5). 
programa socialista para las Elecciones Autonómicas de 1980, redactado por el mismo Solchaga ${ }^{38}$.

La incorporación de Treviño a Alava y, por tanto, a Euskadi, se basó en la voluntad y en el sentir popular de los vecinos de Treviño. Si la voluntad de plena reintegración ya se había manifestado hacía años, ahora lo que se pedía en concreto era la incorporación administrativa a Alava. La estrategia reivindicativa del PNV según el Diputado General de Alava, Alberto Ansola, consistía en el establecimiento desde las Instituciones alavesas de convenios de colaboración social y cultural y en el ofrecimiento de «su inclusión como al resto de los pueblos de Alava en todas nuestras campañas de promoción y desarrollo cultural, técnico y cuantas iniciativas demandan los colectivos sociales de Treviño» ${ }^{39}$. Se trataba de crear las condiciones para que la Administración central, que carecía de argumentos para mantener sus tesis de la pertenencia de Treviño a Castilla, se viese en la necesidad de solucionar de una vez por todas el problema de Treviño ${ }^{40}$.

Sobre la droga se defendió la necesidad de mano dura contra quienes colaboraban o participaban en el tráfico y venta de drogas, la armonización de los códigos penales en los Estados de la Comunidad Europea en cuanto al tráfico de las mismas, disposiciones legales, que permitiesen la incautación y confiscación de dinero y bienes obtenidos del tráfico de droga, y el desarrollo de programas de formación e información con finalidades preventivas. «El uso y abuso de drogas en la sociedad vasca — dijo el candidato al Senado del PNV en Alava, Manuel Allende,_- está evidenciando auténticos dramas en muchas familias de Euskadi que ven cómo se ha deteriorado su calidad de vida, tanto desde el punto de vista económico, como humano y sanitario» ${ }^{41}$.

La cuestión de la corrupción política fue tratada a instancias de entrevistador; no fue tema propiamente de campaña. La idea básica era que la corrupción afectaba a los otros Partidos Políticos, aunque no se citó a todos ellos, y que les afectaba, porque sus campañas descompensaban cualquier presupuesto. El problema era, se concluía, de financiación de los Partidos, aunque mejor habría sido decir que el problema estaba en el colosalismo de las campañas o, simplemente, en el exceso de gastos electorales. La actitud del PNV era favorable a las comisiones de investigación, excepto cuando se trataba de temas que estaban sub judice, para

\footnotetext{
38 Deia 22-V-93 (3).

39 El Correo 3-VI-93 (32).

40 Ibídem.

41 El Correo 22-V-93 (32).
} 
evitar un juicio paralelo. Como en el Parlamento Vasco el PNV se había opuesto a la creación de una comisión de investigación sobre el caso de los tragaperras, Anasagasti comentó: «Aquí, según mi información, fue un planteamiento administrativo llevado un poco a la ligera y que, indudablemente, al PNV le ha acarreado unos costos de imagen. Y el PNV no tiene nada que ver en ese tema» ${ }^{42}$.

Muy poca atención se dedicó a dos temas muy queridos por el nacionalismo del PNV, el del europeísmo y el de la democracia cristiana. El primero fue mencionado por Arzalluz con ocasión de su presencia en Aquisgrán como invitado a la ceremonia, en la que Felipe González recibió el premio Carlomagno. Tal vez, con demasiadas ínfulas y con más carga de crítica que de objetividad, el invitado nacionalista se refirió a su defensa de Europa «cuando otros estaban intentando la revolución o cómodos con la dictadura $»^{43}$. Hay, también, una alusión a la Europa federal en las palabras dedicadas por Anasagasti a la democracia cristiana y a la pertenencia del PNV a ella. En tales palabras, fundamentalmente críticas contra el Partido Popular, como se tendrá ocasión de ver, se atribuye a la democracia cristiana haber sido la impulsora de la Europa federal, además de ser un movimiento centrado en la defensa del hombre y de su entorno, movimiento bien diferente del que representaban los liberales centrado en la defensa de intereses ${ }^{44}$.

Menos espacio ocupó aún el tema de la insumisión y del servicio militar. Se defendió un ejército profesional europeo; se rechazó el servicio militar obligatorio y se interpretó el año de servicio militar como una pérdida de tiempo «en algo tan ineficaz como aprender a manejar las armas» ${ }^{45}$.

\section{La estrategia del PNV ante un posible Gobierno de coalición}

Este tercer apartado, que he calificado en la Introducción de cuestiones estratégicas y de Gobierno, estuvo fundamentalmente acaparado por la expectativa, que crearon las encuestas de opinión del voto al anunciar un resultado electoral bastante igualado en escaños para los dos primeros partidos, el PSOE y el PP, y sin ganador por mayoría absoluta, lo que en

42 El Correo 31-V-93 (22).

43 El Correo 21-V-93 (24). Ver, también. Deia 2-VI-93 (6) y 4-VI-93 (5).

44 El Correo 31-V-93 (22).

45 El Correo 31-V-93 (23). El texto completo, unas declaraciones de Anasagasti, decía: «Creo que me declararía insumiso de todos los ejércitos, porque nosotros somos partidarios de un ejército profesional europeo. No debe existir un servicio militar obligatorio y los jóvenes no deben perder un año de su vida en algo tan ineficaz como aprender a manejar armas». 
términos de la razón de ser de un Partido Político significaba, en principio, el reparto del poder del Estado en un Gobierno de coalición y la conversión, tal vez, de un Partido pequeño en partido visagra. Hasta tal punto adquirió para el PNV importancia esta cuestión que toda la campaña, no sólo lo dicho expresamente sobre la coalición, estuvo condicionado por ella. En cierto modo se podría decir que las encuestas determinaron la campaña nacionalista.

En este punto más que en otros conviene seguir un orden estrictamente cronólogico, que posibilite clarificar la postura del PNV.

En un primer momento el lenguaje fue amenazante, dramático, algo heroíco, altanero y despectivo. El PNV no estaba «dispuesto a vender Euskadi» para formar parte del Gobierno central. La frase respondía a las críticas de quienes interpretaban un posible pacto de Gobierno con el PNV como la venta de España al nacionalismo vasco. «Tengan mucho cuidado con lo que dicen, ya que no estamos pirriados» por semejante proyecto. «Ahora andan sin querer vender España. Pues que se la queden», sentenció Arzalluz ${ }^{46}$.

El origen de semejante actitud parecía estar en las palabras pronunciadas por José María Aznar en su visita al País Vasco: «No venderé España a los nacionalistas». Aunque según el líder nacionalista esta frase tenía la finalidad electoral de captación del voto no nacionalista, sin embargo, daba juego para más gruesas afirmaciones, advertencias y recomendaciones en la línea de la más pura estrategia, por llamarla de alguna forma, nacionalista. Así pudo decir: «Simplemente les pido que tengan cuidado, y que vaya por delante que los vascos, hoy, no necesitamos al Estado, porque estamos capacitados para gobernarnos nosotros, en el marco europeo, y mucho mejor que lo que gobierna $\mathrm{Madrid}^{47}{ }_{\gg}$. Por muchas razones el PNV mantenía una postura «prudente y paciente» en sus reivindicaciones; admitía las reglas de juego y respetaba la Constitución, «pero, por favor, que no nos pongan en la tesitura de tener que revisar toda esta actuación ${ }^{48} »$, porque «se nos acaba la prudencia» ${ }^{49}$. Si después de todas las imposiciones sufridas por el País Vasco durante la dictadura «alguien viene hablando de vender España, sólo le digo que tenga mucho cuidado o revisaremos nuestros planteamientos. Los tiempos han cambiado, y lo digo en serio: que no nos intenten humillar, y quienes nos dicen que no nos venden España, que les quede muy claro que nosotros lo que nunca venderemos es Euskadi. O nos toman como

\footnotetext{
46 El Correo 23-V-93 (44). Todas las frases entrecomilladas del párrafo las dijo el Presidente del PNV.

47 El Correo 24-V-93 (26).

48 Ibídem.

49 Egin 24-V-93 (11).
} 
somos o nos dejan, pero que nos lo digan porque ya sabemos qué hacer si nos dejan ${ }^{50} \gg$.

En cuanto a los posibles pactos postelectorales el PNV no mostraba ninguna preferencia de partido, pero exigía dos cosas: Primera, que se reconociese por el Partido ganador que «España es el último Estado de la Comunidad Europea», porque de lo contrario tendría al PNV en la oposición; y segunda, que elaborase una política responsable distinta a la practicada por el Gobierno socialista, que había sido una política falsa. «Lo necesario es hacer los pactos con quienes mejor podamos sacar a este País de la situación en la que está, porque ya está bien de guitarras y castañuelas, y a ver si empezamos a trabajar» ${ }^{51}$.

Estaba claro para Arzalluz que ni el Partido Socialista ni el Partido Popular podrían gobernar solos, pero el Partido Nacionalista Vasco no ponía precio a su posible participación en el Gobierno. Con estas palabras parece que se trataba de salir al paso de declaraciones socialistas, según las cuales el PNV estaba dispuesto a participar en un Gobierno de coalición, si se aceptaba la creación de un Banco Público Vasco. Se apostaba, simplemente, por la gobernabilidad del país ${ }^{52}$. Con más desparpajo llegó a afirmar que al PNV le importaba «un carajo estar en el Gobierno», aunque, si alguien lo propusiera, tendría que ser haciendo «una política sensata» ${ }^{53}$.

La idea de que no podría haber un gobierno monocolor se repitió en otras ocasiones. En el supuesto de una victoria del Partido Popular, el Partido más permeable a una coalición sería CIU. No había que excluir, por otra parte, un acercamiento entre Izquierda Unida y el PSOE. Las críticas de Anguita a los nacionalistas catalanes y vascos querrían manifestar que él también contaba para un Gobierno de coalición ${ }^{54}$. La inexistencia de mayorías absolutas traería como consecuencia, en cualquier caso, la revitalización de la vida política, el aumento de las facilidades para los medios de comunicación en el acceso a la información política y la mejora general de las posibilidades democráticas ${ }^{55}$.

En el programa «Mesa Redonda» de Tele 5 volvió a repetir que el PNV no plantearía en los próximos cuatro años el derecho de autodeterminación. Si, por otra parte, era llamado por el Partido encargado de formar Gobierno, «les presentaremos el programa, y dejaremos al lado nuestras

\footnotetext{
50 Ibídem.

51 Ibídem.

52 Ver: El Correo 25-V-93 (28).

53 El Correo 26-V-93 (29).

54 Ver El Correo 27-V-93 (34).

55 Deia 27-V-93 (5).
} 
preferencias personales o el grado de amistad, porque estas cuestiones no se dilucidan por amistad...; si alguien quiere contar con nosotros, se han acabado las fantasmadas. Tenemos que partir, quitando toda la hojarasca de la realidad del País que en estos momentos es colista en Europa. Una determinada política llevada a cabo por el Gobieno socialista, de mucha vitola, de mucho Sevilla, de mucha cosa, ha hecho olvidar a la gente dónde estamos» ${ }^{56}$. Sin embargo, con respecto al PSOE, añadió: «Hemos estado en el mismo barco contra Franco, hemos estado juntos en el exilio durante cuarenta años, pero eso no quita para que seamos partidos diferentes, con intereses también diferentes y no siempre con una feliz relación ${ }^{57}$. Estas circunstancias no anulaban la posible colaboración «de lleno» con el Partido Popular, siempre que lo que propusiera fuese razonable, real y realista, «cogiendo al toro por los cuernos de lo que este País necesita, sin vitolas, sin fantasmadas...» ${ }^{58}$

Según Anasagasti el primer Partido con el que el PNV pensaba mantener conversaciones para la formación de Gobierno era Convergencia i Unió. Tales palabras respondían al deseo manifestado por Miguel Roca de dialogar con el PNV antes de establecer acuerdos con alguno de los partidos mayoritarios. La pretensión parecía ser una acción común nacionalista ${ }^{59}$.

El nacionalismo vasco del PNV no tenía apenas interés en tener un ministro en Madrid, porque eso era «como no tener nada». Además, había otras formas de apoyar la gobernabilidad del Estado. Como era necesario crear un Gobierno sólido, se estaba dispuesto a apoyar lo que fuera necesario, ya que podría ocurrir que el Partido con más votos no consiguiese formar una mayoría absoluta y fuera el segundo Partido el llamado a gobernar. El posible pacto nacionalista con socialistas o populares no lo rompería el PNV. «Todos dijo - Arzalluz- nos jugamos demasiado en estos cuatro próximos años como para andar con historias. Por eso

56 El Correo 28-V-93 (30). Las mismas ideas e, incluso, los mismos términos utilizó Arzalluz en el acto central de la campaña del PNV en Navarra. La colaboración del PNV en un futuro Gobierno exigía, como primera condición, el abandono de los discursos habituales oficiales, el reconocimiento de la situación del Estado y la consideración de España como un País «colista» entre los desarrollados, ya que ocupaba el lugar número 23 en el mundo y el último de los de cierta dimensión dentro de la Comunidad Europea. El Partido, que pidiese la colaboración del PNV, debía dejarse de «vitolas y fantasmadas y (explicar) al pueblo la realidad del Estado español» (El Correo 30-V-93, 40).

57 Ibídem.

58 Ibídem.

59 Ver El Correo 28-V-93 (30). Todas estas ideas se encuentran, también, expuestas en Deia 29-V-93 (5). Sobre los temas generales de la campaña ver El Mundo del País Vasco de 25-V-93 (6). 
me hace mucha gracia cuando alguien habla de vender España a los nacionalistas. Como no acertemos la próxima legislatura no va a haber quien compre España» ${ }^{60}$.

En las mismas tesis insistió Joseba Zubia, Consejero de Presidencia y Desarrollo Autonómico del Gobierno Vasco, cuando dijo que si el PNV era llamado para apoyar la formación de un Gobierno tras las elecciones no exigiría «privilegios para Euskadi, sino que se (respetase) total y absolutamente el Estatuto de Gernika» ${ }^{61}$.

Todo esto es compatible con la advertencia de Ardanza dirigida al Partido Socialista de que España debía tener bien claro que «el PNV no sirve a ningún señor, sólo a su patria, que es Euskadi», con lo que se quería afirmar que el Partido Nacionalista no estaba ligado por el Pacto de Gobierno con los socialistas en el País Vasco a pactar únicamente con ellos y, además, que el apoyo al gobierno de España era beneficioso en sí mismo para Euskadi. Todo dependía de los resultados electorales y de un posible proyecto común con el Partido Popular. En cualquier caso, Ardanza y Arzalluz expresa o tácitamente manifestaban que de facto y por un «ahora» de cuatro años el futuro y el bien de Euskadi estaba en la recuperación y en el buen gobierno de España ${ }^{62}$.

El cierre de campaña destapó literatura triunfalista y reivindicativa. «Va a ser un momento culminante — dijo Anasagasti en el Pabellón de La Casilla de Bilbao ante miles de afiliados, al parecer, falto de la más elemental información- de nuestro acontecer político desde la República; tendremos un juego parlamentario como el que no hemos tenido nunca» ${ }^{63}$. También el Lehendakari Ardanza pronosticó una gran oportunidad para Euskadi, al decir: «Esta vez no van a poder pasar olímpicamente de nosotros. Tendrán que volver a pactar y Euskadi va a dejar sentir su peso en la política general del Estado» ${ }^{64}$. Según Ardanza, la reducción del juego polí-

60 El Correo 1-VI-93 (33).

61 El Correo 4-VI-93 (30). Como Borrel había manifestado que el Gobierno central no pensaba transferir a las Comunidades Autónomas la gestión de los puertos de titularidad estatal, Anasagasti comentó que «a Borrel le quedan quince días para seguir siendo ministro y si después quieren formar un gobierno necesitarán el apoyo de vascos y catalanes y ése será uno de los temas que nosotros no vamos a dejar pasar por debajo de la mesa» (El Correo $21-\mathrm{V}-93,29)$.

62 Ver El Correo 31-V-93 (25). Ver en El Mundo del País Vasco 23-V-93 (7) la carta de Ardanza firmada como Lehendakari en folio con membrete del PNV, en la que pide el voto para el nacionalismo y, de una manera implícita, para el PNV.

63 El Correo 5-VI-93 (23). Ver, también, la amplia información aparecida en Deia 5-VI-93 (3 y 4) sobre las intervenciones de Ardanza, Arzalluz y Anasagasti en el pabellón de La Casilla.

64 Ibídem. Ver toda la página 8 de Deia 4-VI-93, donde Ardanza manifiesta que «los vascos tenemos la oportunidad de recuperar el protagonismo y peso que tuvimos en el Estado». 
tico durante la campaña a las dos primeras fuerzas políticas no expresaba la realidad «El auténtico partido se jugará en otra cancha la misma noche de las elecciones y uno de los finalistas de ese partido será Euskadi» ${ }^{65}$.

Las palabras de Arzalluz a El País expresaban un tono muchísimo más moderado y humilde. «No somos chantajistas, nuestro peso electoral en el conjunto del Estado es modestísimo y por lo tanto tras el 6 de junio sólo nos cabe esperar a ver si nos llaman» ${ }^{66}$.

La última intervención sobre este tema la tuvo Arzalluz en la misma concentración de La Casilla repitiendo, en parte, tesis conocidas y, en parte, haciendo afirmaciones contradictorias con las dichas anteriormente. La imagen de sensatez política, de sentido de Estado y de desinterés, que se quería manifestar con la disponibilidad del PNV a apoyar la estabilidad del Gobierno central, contrasta con la afirmación de que «la realidad es que vamos a Madrid, porque todavia no está el Estatuto completo» ${ }^{67}$.

No contrasta, porque era pura repetición, la indignación teatral que manifiestan las palabras dirigidas tanto al Partido Socialista como al Partido Popular: «Formen una mayoría patriota si tanto miedo nos tienen a los nacionalistas» ${ }^{68}$. Lo mismo cabe decir sobre el desinterés del PNV en formar parte del Gobierno y sobre el tono amenazante, que expresa este texto: «Nosotros no daremos un solo paso, y no sé qué tendrá que pasar para que alguien del PNV pueda estar en el Gobierno de Madrid. Yo creo que no hay nada que pueda pasar. Y os digo la verdad: este partido y yo nunca olvidaremos en nuestros cálculos políticos de futuro lo que hemos oído estos días: la venta de España, la compra de Gobiernos, el patriotismo del PSOE y el rechazo que hemos tenido de tantos políticos y de tantos sectores de la población. No lo olvidaré nunca» ${ }^{69}$.

Había algo de lógica en unir el tema de la futura coalición de Gobierno con la crítica de la bipolarización de la campaña electoral y del mismo debate televisivo entre Felipe González y José María Aznar. Ya que habría que contar con otras fuerzas políticas después de las Elecciones para crear un Gobierno estable, parecía sensato reclamar la atención

65 Ibídem.

66 El País 1-VI-93 (20).

67 El Correo 5-VI-93 (23). En Deia 2-VI-93 (5) se atribuye a Arzalluz la afirmación de que el apoyo del PNV a un Gobierno central de coalición estaba supeditado a una serie de condiciones: Presencia efectiva de Euskadi en Europa; entrega de lo que es «nuestro, la Seguridad Social, el INEM y demás». González Txabarri destacó los siguientes elementos de negociación: Política económica, orientación europeísta del Gobierno, transferencia inmediata de los 55 contenidos pendientes, pacificación de Euskadi desde la solidaridad y generosidad y solidaridad económica internacional con los países del Tercer Mundo (Deia 2-VI-93, 6).

68 Ibídem.

69 Ibídem. 
sobre lo que tales fuerzas representaban y defendían. Por ciertas acusaciones contra la Prensa, cabe pensar que la crítica de la bipolarización se hacía contra la información que aquélla daba de la campaña por excesivamente centrada sobre los dos primeros Partidos, dejando de lado a los demás, especialmente a los nacionalistas. Sin duda alguna se hizo esta crítica a los medios de comunicación de masas en general, aunque en lo que respecta a las fuentes que se utilizan en este trabajo hay que decir que no es objetiva esta interpretación, si se entiende la acusación como ocultación de la realidad. Hubo, por supuesto, una mayor información sobre los dos grandes Partidos, pero no se ocultó la campaña de otros Partidos y, en concreto, la de los Partidos nacionalistas. Lo que ocurrió, ciñéndome a los nacionalistas y, ahora, al PNV, fue que este Partido dijo muy poco, que tuviese relevancia programática en todo el ámbito estatalnacional, si se exceptúan las frases retóricas y las críticas a los grandes Partidos, tal y como se verá más adelante. Hubo mucho de impotencia, de simplificación y de rabieta mal contenida por el poco papel, que podía jugar el PNV, al margen de las fanfarronadas ${ }^{70}$.

Las elecciones generales a Cortes, «dijeron los políticos nacionalistas, eran también vascas, lo cual era obvio ${ }^{71}$, pero con ello se quería decir lo que clarificó Ardanza al manifestar su rechazo por la presentación de la campaña como una pugna entre dos partidos, ya que «sabemos muy bien que, en los asuntos que realmente nos importan, la alternativa para Euskadi no depende de la alternancia en el Gobierno de Madrid, sino de la fuerza que tiene el nacionalismo para condicionar y orientar la política del Estado» ${ }^{72}$. González Txabarri ya había especificado la importancia de la presencia de un Grupo vasco en el Congreso. «Los que apostamos por un proceso de diálogo y negociación, por no dejar heridas abiertas y el final de la violencia, entendemos que es muy importante que exista un Grupo vasco capaz de mantener el texto del Acuerdo de Ajuria Enea sin partidismos» ${ }^{73}$.

70 Aunque a veces resulta difícil la separación, ciertos testimonios en los que se acusa a la prensa de parcialidad y falta de independencia los hemos incluido en la crítica a los Partidos mayoritarios, donde se mezclan cuestiones a las que ahora mismo se hace referencia. Sobre el tema de la prensa Arzalluz dijo: «Sabemos que El País apoya al PSOE, y el ABC al PP, y El Mundo apoya al PP, y el diario Vasco apoya al PP, y El Correo Español apoya al PP. Ya sabíamos que Egin apoyaba a HB y que Deia al PNV, pero hemos visto que los demás también, luego no hay prensa independiente» (Egin 31-V-93, 14).

71 Ver El Correo 21-V-93 (29).

72 El Correo 24-V-93 (26).

73 El Correo 23-V-93 (44). La doble finalidad inicial de este texto, pedir el voto para el PNV y negárselo a HB, por su inasistencia al Congreso, no anula su utilización en el sentido en que se hace.- La importancia de un grupo parlamentario vasco justificaba la petición del voto a simpatizantes de EA y EUE y fue destacada en diversas ocasiones, v.g. Deia 3-VI-93 (5). 
Para Ardanza la polarización de la campaña electoral entre los candidatos del PSOE y PP resultaba ridícula, ya que la suma de votos y escaños del PP y PSOE en el País Vasco equivalía a la del PNV (afirmación totalmente falsa) de manera que «con estos datos se detecta la incidencia que ese bipartidismo puede tener entre nosotros» ${ }^{74}$. Era preocupante para el Lehendakari que se pretendiese generar «una cultura política que no se (adecuaba) ni al marco legal, ni al marco jurídico, ni a la ley electoral» ${ }^{75}$.

Según El Correo, Arzalluz manifestó su criterio contrario - no era la primera vez- a la celebración de debates electorales entre los candidatos de los dos primeros Partidos, en los que se excluyese a los de otras formaciones políticas, ya que se atacaba con ello a las reglas de juego, eliminando «una mínima igualdad de oportunidades a los grupos parlamentarios ${ }^{76}$. La postura de la Junta Electoral Central aprobando tales debates merecía ser contestada con la retirada de las elecciones de los Partidos excluidos $^{77}$. También Anasagasti criticó el debate, presentado como debate entre Gobierno y oposición. «Nosotros — dijo- somos también miembros de la oposición y él (Aznar) no es nuestro jefe. Se quiso presentar un debate entre Gobierno y oposición, cuando estamos en un sistema proporcional y no mayoritario» ${ }^{78}$.

La crítica más sabrosa al debate entre González y Aznar, en lo que afecta a la imagen del PNV que ahora se trata de dibujar, corrió a cargo del portavoz del PNV, Joseba Egibar, quien, además de calificar al acto de «burla del sistema», brindó con muy poca lógica, ya que los Partidos excluidos eran más de dos, la colaboración nacionalista para un debate a tres o cuatro bandas o como quisieran. Este ofrecimiento proponía, incluso, un debate «a dos con Xabier Arzalluz», que no sería aceptado según anunciaba ya el mismo Egibar, porque «la visión de estadista, de lo que puede ser conexión con Europa, lo que es la implicación no sólo de nuestro país, sino de regiones y nacionalidades que nos rodean, el engarce de todo esto en Europa, que es el futuro en definitiva, (sic) todavía no hemos visto ninguna aproximación a lo que puede ser el nivel de exposición que ha tenido el presidente del PNV» ${ }^{79}$. De acuerdo con esto, se entendía lo declarado a continuación, aunque la razón esgrimida brillase

74 El Correo 28-V-93 (30). Ver, también, Egin 31-V-93 (13): «En Euskadi esta historia del bipartidismo no funciona; no se han dado cuenta de que en este País entre los dos juntos no suman más que el PNV solo».

75 Ibídem.

76 El Correo 30-V-93 (40).

77 Ibídem. Ver, también, Egin 30-V-93 (17).

78 Deia 25-V-93 (3).

79 El Correo 2-VI-93 (28). 
por su ausencia durante la campaña: «Es curioso que nos estén llamando desde distintos puntos del Estado español, que hayan dado con el teléfono de nuestras sedes para preguntar si nos presentamos en Salamanca, Segovia o Madrid porque quieren votar al Partido Nacionalista Vasco, y no precisamente porque seamos españoles, sino porque damos en las claves, porque abordamos los temas con sinceridad, con realismo» ${ }^{80}$.

\section{B) La crítica de los Partidos Políticos}

El Partido más criticado y atacado fue el Partido Popular con un $43 \%$ de este apartado. Mientras el PNV basaba la propaganda en torno al reparto del poder tras unas elecciones sin vencedor mayoritario, la campaña se desarrollaba según los medios de información centrada sobre los dos grandes Partidos. Según esto, la denuncia estaba servida. La bipolarización de la campaña entre el Partido Socialista y el Partido Popular, por una parte, y, por otra, su manifestación más expresiva, el debate televisivo entre los dos candidatos a la Presidencia del Gobierno, Felipe González y José María Aznar, constituyeron la crítica más abundante, en la que destaca la poca rigurosidad de los argumentos utilizados, si no la ocultación o falsedad de los mismos, tal como se ha visto más arriba.

Arzalluz aprovechó el tema para acusar a la prensa de clientelismo político y de falta de independencia. «En este momento — dijo- no hay prensa independiente ni en España ni en Euskadi». El bipartidismo de la campaña iba en beneficio del Partido Popular y del Partido Socialista e implicaba «una falta de respeto al nacionalismo». La práctica común en ambos líderes de reducir Euskadi a un espacio en el que recoger votos constituía, así mismo, un desprecio para el País Vasco ${ }^{81}$.

Los agravios recibidos por el PNV en la campaña, que fundamentalmente se resumían en la marginación del PNV, justificarían la sugerencia del Presidente del PNV dirigida a socialistas y populares de que formasen juntos «una mayoría patriota» 82 .

Por su parte, el debate en la Televisión entre los líderes de los Partidos mayores, del que se había excluido a los demás grupos políticos, era algo inaceptable. Arzalluz no lo vio en señal de protesta por semejante exclusión y manifestó su incomprensión de que la Junta Electoral Central lo hubiese autorizado. "No estamos en América - dijo- donde sólo hay dos candidatos. Aquí se está eligiendo un Parlamento en el que no habrá mayorías absolutas». Semejante hecho no se habría tolerado en

\footnotetext{
80 Ibídem.

81 El Correo 31-V-93 (25).

82 El Correo 5-VI-93 (23).
} 
el resto de las democracias europeas. La situación era «de pura incultura política» ${ }^{83}$.

A diferencia de Arzalluz, que no vio ninguno de los dos debates televisados, Ardanza prometió ver, por lo menos, el segundo, al que ridiculizó en estos términos: "Vamos a ver si al final el debate lo hacen de pie o sentados, si se miran a los ojos, si miran a la cámara, al cielo o al suelo, porque todo eso debe ser muy importante, deben ser los grandes temas que en este momento se están debatiendo» ${ }^{84}$.

La descalificación del debate fue la moneda común entre los nacionalistas. Egibar lo calificó de «show» y de «hueco», añadiendo que la mayoría de los espectadores desconectó en el intermedio y se fue a la cama. Sin embargo, lo que fue una sorpresa para el Consejero de Presidencia y Desarrollo Autonómico, que no se hiciera ninguna mención a la cuestión autonómica en los debates televisados ${ }^{85}$, fue agradecido por Egibar, porque, según parece, de esa manera los Partidos quedaban más libres para después tratar con el PNV en la futura coalición de Gobierno los problemas autonómicos ${ }^{86}$.

La marginación y olvido del PNV en la estrategia popular ${ }^{87}$, que era el verdarero problema de fondo denunciado por los nacionalistas, se unió con el antivasquismo y antiautonomismo del Partido Popular. El desuso del euskera, el desprecio del nacionalismo, la escasa o nula sensibilidad autonómica y la intención de no transferir, en concreto, competencias penitenciarias confirmarían la imagen antiseparatista, que el Partido Popular pretendía transmitir con la finalidad de atraer el voto del electorado no nacionalista. Por todo ello el Partido Popular podía ser culpable de cambios en la política moderada y prudente del nacionalismo del $\mathrm{PNV}^{88}$.

La oposición al Partido Popular se apoyaba también en su indefinición ideológica ${ }^{89}$, en su programa menos positivo que el del PSOE y en

83 El Correo 26-V-93 (29).

84 El Correo 31-V-93 (25).

85 Ver El Correo 4-VI-93 (30).

86 El Correo 2-VI-93 (28).

87 Iñaki Anasagasti manifestó que Aznar no consultó ni a los nacionalistas catalanes ni a los vascos su pretensión de conseguir una vicepresidencia del Partido Popular Europeo. Prefirió el «baño europeísta» que llevarse bien con vascos y catalanes. Era un error de estrategia según el político nacionalista (Ver El Correo 31-V-93, 22).

88 Ver: El Correo 24-V-93 (26); 26-V-93 (29); 31-V-93 (25); 4-VI-93 (30); 5-VI-93 (23).

89 La indefinición vendría dada por las distintas corrientes dentro del PP, donde predominarían, no obstante, las tesis conservadoras a pesar de los esfuerzos del propio Aznar. Esto es lo que manifestó sobre la cuestión y sobre las diferencias con el PNV Anasagasti: «La democracia cristiana ha sido la impulsora de la Europa Federal y, claro, cuando vemos a Aznar fotografiándose con Chirac y Thatcher, que son más partidarios de la Europa de los Estados hay una diferencia fundamental. Los liberales hacen más hincapié en los intereses y la democracia 
la consideración de que la alternancia en el Gobierno central era indiferente a los intereses de Euskadi ${ }^{90}$.

Las palabras de Aznar, que manifestaron su rechazo a la rehabilitación de presos de ETA condenados por delitos de sangre, provocaron las reacciones más violentas entre los nacionalistas. Según Ardanza, con ello se cuestionaban de nuevo los puntos 9 y 10 del Pacto de Ajuria Enea, firmados por los Partidos Políticos, entre los cuales estaba el Popular. Arzalluz protestó de que Aznar se pusiera en plena campaña «el Pacto de Ajuria Enea por montera» y pidió que manifestara públicamente si ratificaba o no el acuerdo de los Partidos ${ }^{91}$. Al final de la campaña el Presidente del PNV insistió sobre el tema con palabras muy graves: « ¿Y si gana el PP, cuándo saldrán los presos? Por lo visto los del PP no pensaban transferir las competencias penitenciarias. Es bueno que tome nota Atutxa. Lo que se está viendo es que, por ejemplo, Mayor Oreja, que vive en Madrid y está aquí, va haciendo carrera política a cuenta de ETA, de los presos y de la autovía. Está haciendo carroña, está rompiendo el Pacto de Ajuria Enea. Y lo que dice en campaña va a quedar también guardado y grabado, y veremos después quién pide cuentas a quién $\gg^{92}$.

«Irresponsable» fue el calificativo que Arzalluz dedicó a la actitud de Aznar en la reunión de las formaciones democristianas europeas. «Fue a por la foto y ni estuvo en los debates ni se enteró de nada». En su opinión, la estancia de una sola hora en una reunión, que tenía por objetivo el análisis de la situación internacional, constituía un engaño $0^{93}$.

cristiana, en el hombre y su entorno. Aznar se está acercando, pero todavía hay gente en el seno de su partido que no está por la labor.... creo que el José María Aznar de 1993 no tiene nada que ver con el Iñigo Cavero de 1977 (El Correo 31-V-93, 22). Días antes, al comenzar la campaña y al explicar la negativa del PNV a apoyar la candidatura de Aznar a una de las Vicepresidencias del Partido Popular Europeo, Anasagasti dijo que se debió a la indefinición ideológica del Partido Popular. Se calificaba de hombre honesto a Aznar y se reconocía sus esfuerzos por centrar al PP y hacerlo democristiano, pero la apuesta simultánea por los conservadores, los liberales y los demócratas cristianos constituía una «ensalada», donde lo ideológico quedaba en segundo lugar (Ver El Correo 21-V-93, 29). El mismo Anasagasti manifestó que «la extrema derecha estricta la tenemos calladita, esperando su oportunidad, en el voto del Partido Popular» (Deia 29-V-93, 5).

90 Ver: El Correo 21-V-93 (29); 23-V-93 (44); 24-V-93 (26).

91 El Correo 22-V-93 (12). Según Jaime Mayor Oreja, Presidente del PP en el País Vasco, las palabras de Aznar no aportaban ninguna novedad a las tesis defendidas por el PP en la materia. La reacción de Ardanza se debería a que «poco o nada tiene que decir del gran dilema y debate de esta campaña y prefiere introducirse en este asunto magnificando otras cuestiones» (Ibídem).

92 El Correo 5-VI-93 (23). No faltaron veladas acusaciones contra el Partido Popular y, también, contra el PSOE de posibles irregularidades legales en materia de financiación de la campaña electoral (Ver: El Correo 31-VI-93, 22).

93 Deia 4-VI-93 (5). 
El PSOE atrajo en segundo lugar (33\%) la atención crítica nacionalista. Esta tuvo en ciertos aspectos los mismos contenidos que la dirigida al Partido Popular, es decir, todo lo relativo a la bipolarización de la campaña, al intento de creación de una cultura política de bipartidismo, a la marginación del nacionalismo y al debate en televisión ${ }^{94}$, pero añadió, como era lógico, la denuncia de la política socialista en el Gobierno, especialmente, su política industrial y económica. Esta había sido nefasta para el País Vasco. En este sentido se manifestó Ardanza: «No quiero hacer sangre contra el Gobierno, pero tampoco puedo eximirle, porque la política económica que ha hecho ha sido nefasta para nuestros intereses» ${ }^{95}$. El Gobierno socialista había favorecido los movimientos especulativos, que habían terminado en «una desastrosa política económica» ${ }^{96}$.

Se reconoció que no podía haber Gobierno que eliminase la crisis económica de golpe, a la vez que se hizo culpable a la política «falsa» y «de listos» de los socialistas la permanencia durante muchos años del paro en España, «un "colista" respecto a Europa»97. Había sido «una buena política para jugar de listos en tiempo de bonanza», manifestó Arzalluz ${ }^{98}$. La política llevada a cabo por el Partido Socialista «de mucha vitola, de mucho Sevilla, de mucha cosa» había hecho que la gente olvidase dónde se encontraba ${ }^{99}$. Había sido una política triunfalista, que había adormilado al pueblo, pero «cuando se ha pinchado el globo, cuando se ha deshinchado el "soufflé", se ha visto que había mucho aire y poco huevo»" 100 .

En el mismo tono acusatorio se dijo que la construcción de la miniacería en sustitución de los Altos Hornos «que nos van a derribar» dependía únicamente del compromiso de Felipe González. En el mitin de Barakaldo, prácticamente dedicado a enjuiciar la labor del Gobierno central, llegó a decir el presidente del PNV que «nos han estado matando la industria por financiar los fastos del Estado», mientras el PNV luchaba por salvarla frente a Solchaga y Aranzadi. Así mismo, denunció que el agujero negro del Estado llevase a reducir los gastos sociales. «Nosotros estaremos contra eso. Habrá que subir los impuestos indirectos al tabaco, al alcohol, al lujo y al vicio, no a la renta, ni a la gente, porque nosotros

94 Ver textos citados para el caso del Partido Popular.

95 El Correo 24-V-93 (26).Ver, también, en Deia 29-V-93 (3) el mitin de Barakaldo, en el que se hace culpable al PSOE del desmantelamiento industrial de la margen izquierda y de incompetencia. «Algunos creen — dijo Arzalluz - que por tener carnet del Partido Socialista pueden pilotar aviones...»

96 Ibídem.

97 Comentario de Arzalluz en El Correo 26-V-93 (29).

98 El Correo 27-V 93 (34).

99 El Correo 28-V-93 (30).

100 El Correo 30-V-93 (40). Fueron, también, palabras de Arzalluz. 
procedemos de este pueblo. El vasco nunca ha pactado con la miseria y el PNV nunca ha flaqueado en lo social» 101.

Ardanza declaró en los actos conmemorativos del Día de Galicia en Euskadi que «en pocas cosas existe tanta unanimidad en este País como en el suspenso que se ha ganado la política económica del Gobierno central al abandonar la economía productiva y dar vía libre a la especulación» ${ }^{102}$.

El PSOE recogió, también, las mismas acusaciones que el PP en materia de antivasquismo, falta de sensibilidad autonómica, desprecio y marginación del nacionalismo, campaña de agravios contra el Partido Nacionalista y de posible responsabilidad de futuros cambios estratégicos del nacionalismo moderado ${ }^{103}$.

No obstante la defensa de una política de estabilidad en el Gobierno central, que el PNV decía apoyar de una manera desinteresada, se advirtió que el apoyo a los socialistas dependía de determinadas transferencias, siempre haciendo coincidir la alianza con los socialistas con el bien y el provecho de Euskadi. Pero no debía extrañar a nadie que el PNV pactase con otros partidos, tales como el Partido Popular ${ }^{104}$.

Hubo, por fin, algunas palabras de reconocimiento hacia el Partido Socialista, que mostraban la preferencia de su triunfo en las elecciones. Se prefería su programa por encima del programa popular; de ahí que la afirmación de que era irrelevante la alternancia de Partido en los órganos centrales de Gobierno fuese contradictoria. Por otra parte, se reconoció a través de Arzalluz que «hemos estado en el mismo barco contra Franco, hemos estado juntos en el exilio durante cuarenta años», para añadir que «esto no quita para que seamos partidos diferentes, con intereses también diferentes y no siempre con una feliz relación ${ }^{105}$.»

Herri Batasuna, el tercero de los partidos o coaliciones electorales criticado por el PNV con el $14,78 \%$ de espacio, fue considerado como una realidad, que amenazaba hegemonizar Guipúzcoa, por lo que se llamaba a evitar semejante resultado, ya que su voto era inútil para los intereses vascos y respaldo, a su vez, para realizar cosas repugnantes según el Consejero de Interior, Atutxa ${ }^{106}$. A Herri Batasuna la definia el incivis-

101 Deia 29-V-93 (3).

102 El Correo 31-V-93 (25).

103 Ver lugares citados en el caso del Partido Popular. Ver, así mismo, Deia 29-V-93 (5), donde Egibar acusa a Fernando Buesa de «provocar» con sus declaraciones sobre la confluencia de las Ikastolas en la red Pública. El Departamento de Educación consideró «una tergiversación interesada» las palabras de Egibar.

104 Ver El Correo 21-V-93 (29) y 31-V-93 (23 y 25).

105 El Correo 28-V-93 (30). Ver, también, El Correo 23-V.93 (44); 24-V-93 (26).

106 El Correo 23-V-93 (44). 
mo, el desprecio y ataque a los derechos y libertades públicas, la incitación al enfrentamiento civil, la explotación de los presos de ETA, la extorsión de los empresarios y la responsabilidad de la situación vasca, en concreto, de la recesión económica, con un proyecto de convertir Euskadi en una nueva Albania ${ }^{107}$.

Egibar acusó a HB de «manipular» el tema de las Ikastolas y de cambiar de política sobre las mismas, pasando de posiciones a favor del carácter público de las Ikastolas a posiciones a favor de Ikastolas privadas ${ }^{108}$.

La reconversión pendiente de $\mathrm{HB}$ era la de convertirse en un partido democrático, que - según Anasagasti- podía ocurrir en la siguiente legislatura. De momento, era la extrema derecha en Euskadi ${ }^{109}$, que hacía pura demagogia con la autodeterminación ${ }^{110}$. González Txabarri manifestó que era «vergonzoso» que HB fuese la primera fuerza política de Guipúzcoa ${ }^{111}$.

La nota irónica la puso Arzalluz en el mitin de su Partido en Barakaldo, cuando, al pasar una manifestación de Jarrai durante la celebración de aquél, interrumpió su discurso para decir: «Aplaudirles. Los pobres es la única forma que tienen de llamar la atención. Son como los cucos, que ponen los huevos en el nido de otros pájaros. A éstos les pasa igual. Tienen que venir a la manifestación de otros, para que alguien los vea»112.

De Unidad Alavesa (7,59\% del espacio) se insinuó el pasado reciente de tipo fascista y caciquil de algunos de sus integrantes, así como la apropiación personal de dinero público en el anterior régimen, pero fundamentalmente se destacó su carácter antivasco. Se le acusó de «despertar viejos demonios susceptibles de crear tensiones, fraccionamientos sociales y exasperación ambiental y política». Ejemplos de todo ello eran su posición ante el euskera y el paro, y su amenaza de sacar a Alava de la Comunidad Autónoma Vasca. El PNV prometió no establecer ningún acuerdo con semejantes foralistas, mientras no cambiasen sus planteamientos. Félix Ormazabal calificó a Unidad Alavesa de «movimiento antivasco, disfrazado de antinacionalista, que (pretendía) destruir Euskadi y

107 Vel El Correo 23-V-93 (44); 26-V-93 (29); 29-V-93 (30); 30-V-93 (40); 31-V-93 (22 y 25).- Ver, también, Deia 27-V93 (4) y 5-VI-93 (3), donde Arzalluz tocó ampliamente el tema de los presos de ETA.

108 Deia 29-V-93 (5).

109 Deia 29-V-93 (5).

110 Deia $30-\mathrm{V}-93$ (5).

111 Deia 2-VI-93 (6).

112 Deia 29-V-93 (3). 
al pueblo vasco». Por su parte Emilio Olabarría lo consideraba «heredero sucesor de la vieja derecha carlista y reaccionaria» con «un concepto insolidario de la foralidad» ${ }^{113}$. Unidad Alavesa jugaba «al voto del miedo a través de prácticas generosamente demagógicas» ${ }^{114}$.

Muy poco se habló de Eusko Alkartasuna. Unicamente para calificar el voto a EA de inútil, para echar en cara a Azkarraga su actitud agria y resentida ${ }^{115}$ y para definir a sus miembros como «gente anti-PNV». «Eso - manifestó I. Anasagasti- lo tienen muy claro y no hay más que ir a un mitin suyo para comprobar que el noventa por ciento de las intervenciones son dedicadas al PNV como una fijación» ${ }^{116}$.

Desde el PNV se pensaba que la escisión protagonizada por EA había sido «traumática» para aquél y «saludable» para $\mathrm{EA}^{117}$.

La coalición EA-EUE no era para González Txabarri más que «una suma de incoherencias» ${ }^{118}$.

\section{La campaña de Eusko Alkartasuna-Euskal Ezkerra (EA-EUE)}

\section{Datos básicos}

La definición o imagen de EA-EUE se elaboró con el $46 \%$ de su campaña. El resto, el 54\%, se dedicó a la crítica de los otros contendientes en las elecciones. Poco más o menos se repitieron los porcentajes ya conocidos del Partido Nacionalista Vasco.

Del espacio dedicado a la imagen de partido sólo el 9\% desarrolló contenidos nacionalistas, entendiendo por tales, con las reservas anteriormente ya indicadas, las cuestiones autonómicas y de autodeterminación. Más de la mitad (56\%), por el contrario, estuvo centrada en la exposición de contenidos programáticos e ideológicos ajenos a la ideología nacionalista como tal, entre los que destacan la política económica (22,52\% de la imagen), la regeneración de la vida política $(12,41 \%)$, la juventud $(7,58 \%)$, la pacificación y la normalización de la sociedad vasca $(5,97 \%)$, la mujer $(3,9 \%)$ y el problema de la reinserción $(3,44 \%)$. El 35\% restante lo ocuparon cuestiones de gobierno, pactos postelectorales, partido y coaliciones.

Como ha podido observarse, bastantes de estos porcentajes resultan insignificantes en el total de la campaña. Esto ocurre, por ejemplo, con el

\footnotetext{
113 El Correo 29-V-93 (30). Ver, también, El Correo 1-VI-93 (33) y Deia 2-VI-93 (6).

114 Deia 4-VI-93 (6).

115 Ver El Correo 29-V-93 (30); 31-VI-93 (23).

116 Egin 27-V-93 (16).

117 Deia 25-V-93 (5).

118 Deia 2-VI-93 (6).
} 
apartado de la ideología nacionalista, que en una perspectiva general no ocupa ni el 5\% de la atención.

Por lo que dice relación a la crítica de los Partidos Políticos, el 47,15\% recayó sobre el Partido Nacionalista Vasco; el 41,84\%, sobre el Partido Socialista-Euskadiko Ezkerra; el 9,62\%, sobre Herri Batasuna, y, por último, el 1,37\%, sobre el Partido Popular.

Los actores políticos (téngase en cuenta que se hace la medición con prensa editada para Bilbao) de esta campaña y sus participaciones fueron las siguientes: Azkarraga, con el 42,46\%; Garaikoetxea, con el 39,25\%; Albistur, con el 6,17\%; Baztarrika, con el 4,44\%; Oliveri, con el 2,46\%; Oregui, con el 1,97\%; Aulestia, con el 1,97\%, y Gurrutxaga con el 1,23\%.

\section{Desarrollo de la campaña}

A) La definición e imagen de Partido (Coalición electoral)

1. La ideología nacionalista

Estatuto, autogobierno y autodeterminación fueron los conceptos políticos manejados por EA-EUE. Sobre el primero se defendió la especificidad del Estatuto Vasco y la lógica consecuencia de rechazar la igualación de las competencias de los Estatutos de las demás Comunidades Autónomas. Además, puesto que se había perdido el sentido originario del Estatuto Vasco de Autonomía, hacía falta recuperarlo para que la sociedad vasca volviera a confiar en sus instituciones de autogobierno.

Hay en esta exposición una doble interpretación del Estatuto de Autonomía. Inicialmente se le identifica con el autogobierno y posteriormente con la mera descentralización administrativa, aunque no se usa esta palabra. Como el Estatuto, en cuanto texto jurídico, no se había reformado, hay que entender que lo que había cambiado es la voluntad política, la fuerza y la orientación de la voluntad política en la interpretación, aplicación y desarrollo del mismo, que habría evolucionado desde posiciones favorables a la distribución y participación del poder del Estado por la Comunidad Autónoma Vasca a posiciones restrictivas más propias de una interpretación centralista del Estado.

De acuerdo con esto Joseba Azkarraga decía que si se mantenía el mismo criterio de desvirtuamiento del marco autonómico, su coalición trataría de «impulsar un nuevo planteamiento de nuestro derecho al autogobierno basado en la búsqueda de un nuevo consenso mayoritario en el seno de la sociedad vasca» ${ }^{119}$.

119 El Correo 21-V-93 (29). Egin 21-V-93 (6) añadía al intento de impulsar otro consenso el esfuerzo por «desarrollar la soberanía de los vascos». Ver, también, El Correo 25-V-93 (28); 
Cuando se habló del papel, que podía jugar la coalición EA-EUE en un futuro Parlamento muy fragmentado, se consideraron innegociables, además de otras cosas, «la urgente transferencia de las competencias de Régimen Económico de la Seguridad Social, Investigación Tecnológica e Inem» ${ }^{120 .}$

Si bien el concepto de autodeterminación no se utilizó mucho, cuando llegó el momento, se afirmó con rotundidad. Como se atribuía a Arzalluz haber dicho que hablar de autodeterminación en la campaña era hacer demagogia, Carlos Garaikoetxea manifestó que «para un nacionalista defender la autodeterminación nunca es demagogia. Es nuestro abc. Que nadie se llame a engaño. Defendemos y seguiremos defendiendo la autodeterminación y nuestro derecho a ser una nación, porque, antes que nada, somos nacionalistas». Un Estado propio para Euskadi no era un «anacronismo» ${ }^{121}$.

También Azkarraga defendió la autodeterminación, concepto que se entremezclaba con el de autogobierno. Este lo defendía EA no sólo por ser una reivindicación histórica de los nacionalistas, sino por ser «una forma de avanzar en la creación del Estado de bienestar» ${ }^{122}$.

«Ninguna instancia externa al pueblo vasco -manifestó X. Gurrutxaga- puede decidir por nosotros cuál es el final del autogobierno vasco» ${ }^{123}$.

Estos son un lenguaje y un contenido netamente nacionalistas, con todo lo que ello tiene de significación y de consecuencia en el orden de los valores. Pero en la campaña tuvo muy poca relevancia, ya que pasó desapercibido. Lo dicho es nacionalista, pero la campaña en la que se incluyó no lo fue o, más bien, apenas lo fue, a pesar de que se habló de que el nacionalismo en Euskadi era plural ${ }^{124}$.

\section{Cuestiones programáticas}

Destaca en este apartado la atención prestada a la política económica e industrial. Había que impulsar un nuevo modelo de crecimiento económico, en el que el empleo fuera una prioridad. Para ello era necesario in-

4-VI-93 (30). El País publicó dos entrevistas, una hecha a X. Albistur (22-V-93, 6), y la segunda hecha a J. Azkarraga (27-V-93, 6) sobre los temas generales de la campaña.

120 El Correo 2-VI-93 (28).

121 El Correo 31-V-93 (24) y Egin 31-V-93 (12). Ver, también, las manifestaciones de Albistur en Egin 23-V-93 (8 y 9).

122 Egin 21-V-93 (6).

123 Egin 31-V-93 (12). En otra ocasión Gurrutxaga manifestó que «el derecho de autodeterminación le corresponde a Euskal Herria y quienes lo ejercen son los ciudadanos vascos, y eso significa que hay que cambiar la Constitución. En la coalición EA-EUE hay independentistas y no independentistas, no se expresa (sic) por una fórmula concreta, pero también pensamos que el Estatuto de autonomía y la autodeterminación no son incompatibles» (Egin 28-V-93, 14).

124 Ver El Correo 5-VI-93 (25). 
centivar y apoyar a todo el que estuviera dispuesto a invertir en el País Vasco $^{125}$. «El objetivo es claro - manifestó Azkarraga-: generar riqueza. Hemos pasado de estar en los primeros puestos en el ránking del Estado, a estar en el furgón de cola. Hablar de generación de empleo es hablar de industria en este país, y por desgracia nos hemos encontrado con que la Administración, tanto la central como la vasca, ha sido incapaz de generar nuevos proyectos. Por un lado han estado los fastos del Estado y, por el otro, la Administración vasca haciendo seguidismo. Y, mientras tanto, la cabecera de Altos Hornos se ha marchado a Avilés, Astilleros Reunidos está a punto de cerrar, Acenor atraviesa una situación delicada... Hay que revitalizar el tejido industrial, lo que exige bajar los tipos de interés para potenciar la inversión, y afrontar el reparto del empleo. Porque nos vamos a encontrar con que en este País sólo trabaja el $20 \%$ de los ciudadanos y el otro $80 \%$ vive de ese $20 \%$. Antes de que eso ocurra, debemos realizar una revolución de las mentalidades: reducción jornada laboral (sic), incentivar trabajos de utilidad colectiva, reducir los impuestos a los trabajos menos cualificados...»126

Azkarraga defendió la necesidad de la presencia de representantes institucionales vascos en la gestión de empresas públicas ubicadas en Euskadi, así como la presencia de una representación vasca en las negociaciones con la Comunidad Europea en todo lo que afectase a intereses vascos. Su formación política pensaba defender en la siguiente legislatura el mantenimiento de la cabecera de Altos Hornos de Vizcaya «o en su caso la presentación de un proyecto que garantice la actual capacidad productiva y permita conservar el sector siderúrgico de Vizcaya y los puestos de trabajo de las industrias auxiliares» ${ }^{121}$. En cualquier caso los intereses vascos estaban mejor garantizados con representantes en Madrid de la coalición EA-EUE ${ }^{128}$.

El segundo punto en extensión fue el de la regeneración de la vida política vasca. Se le concedió tanta importancia al tema que se revistió de cierta solemnidad la proclamación de EA-EUE en defensa de una política honesta. Los candidatos al Congreso y al Senado de la coalición firmaron una declaración junto al monumento a la paz de Eduardo Chillida en Guernica, en el que expresaban su deseo de renunciar al privilegio de la inmunidad parlamentaria. Se trataba de recuperar la credibilidad ante la opinión pública, variando los «usos, costumbres y actitudes como la

125 Ver El Correo: 23-V-93 (44); 24-V-93 (27); 26-V-93 (29); 27-V-93 (35); 29-V-93 (31); 4-VI-93 (30).

126 El Correo 28-V-93 (34)

127 El Correo 27-V-93 (35). Ver, también. El Correo 2-VI-93 (28).

128 El Correo 28-V-93 (31). 
corrupción, las promesas incumplidas o la manipulación de la voluntad de los votantes». La honestidad, la transparencia, el diálogo y la tolerancia serían los principios de su actuación ${ }^{129}$, es decir, «la verdadera alternativa progresista. Lo hemos desmostrado - dijeron en Bilbao los dirigentes de la Coalición de EA-EUE - en los cuatro últimos años y lo volveremos a hacer en la próxima legislatura. No nos venderemos como otros y trabajaremos para que acaben de una vez tantas prepotencias, chulerías, filesas y tragaperras» ${ }^{130}$.

Sobre la juventud se anunció la propuesta de supresión de las leyes, que penalizaban la insumisión y castigaban la objeción de conciencia, así como la elevación de la edad penal a 18 años. Azkarraga completó el interés de su partido por los jóvenes, «el sector más importante de la sociedad», pidiéndoles que votasen, porque las elecciones también iban con ellos $^{131}$. A estos objetivos se añadió el de la supresión del servicio militar obligatorio. Se pensaba que, debido al alto índice de paro que afectaba a la juventud, casi el 50\%, a la carestía de la vivienda y a la falta de información y soluciones, el desencanto y la frustración dominaban a los jóvenes. EA-EUE pretendía devolver la ilusión y les pedía el voto para un programa, que destacaba el empleo juvenil, la formación en las empresas y medidas fiscales para facilitar el acceso a la vivienda ${ }^{132 .}$

Garaikoetxea y Gurrutxaga unieron el triunfo de EA-EUE, especialmente en Guipúzcoa, con «un impulso trascendental para restablecer el clima de convivencia y la normalización de la vida de nuestra sociedad» y con la «reconciliación y la recuperación de la confianza, en un momento trascendental para la recuperación económica de la comunidad autónoma»133.

Diversos candidatos destacaron ante miembros de la Asociación de Mujeres Profesionales y Empresarias de Guipúzcoa la defensa que su programa hacía de la incorporación de la mujer al mundo empresarial y, en concreto, de la necesidad de aplicar en el mundo laboral el principio de igualdad en las retribuciones y en el acceso a puestos de responsabilidad ${ }^{134}$.

129 El Correo 22-V-93 (33).

130 El Correo 31-V-93 (24). La misma promesa se dijo en otra ocasión: «No venderemos por un plato de lentejas el contenido de nuestro programa electoral, tal como han hecho otros partidos nacionalistas durante la pasada legislatura» (El Correo 2-VI-93 (28). Ver, también, la insistencia de Albistur en la transparencia y honradez demostradas por la Coalición en $E l$ Correo 4-VI-93 (30).

131 El Correo 26-V-93 (29).

132 El Correo 29-V-93 (31).

133 El Correo 3-VI-93 (32).

134 Ver El Correo 28-V-93 (31). 
Sobre el fin de ETA se mantuvo que había que ser muy cauto en asuntos tan delicados. Era cierto que ETA estaba más débil que hacía un año, pero ello no impedía que matase. «Un personaje con una pistola al cinto puede darnos muchos disgustos todavía», manifestó Azkarraga. Se pensaba que la sociedad civil iba aislando a los violentos, pero no se podía poner fechas del fin de la violencia. Por otra parte, la solución a la violencia debía ser dialogada, no traumática, pero teniendo en cuenta que el diálogo no podía entederse como una negociación política, ni podía realizarse al margen de las instituciones políticas y Partidos políticos. Partidarios de la reinserción, se advertía que «no puede plantearse la reinserción a quien no quiere reinsertarse, a quien no quiere terminar con una situación en la que él mismo se ha introducido. De la misma forma que no se puede conceder la reinserción a Amedo, una persona que no se arrepiente de los crímenes en los que ha participado» ${ }^{135}$.

\section{Estrategia política}

Garaikoetxea esperaba que los resultados electorales llevasen a una revisión de la coalición de Gobierno (Partido Nacionalista y Partido Socialista) de la Comunidad Autónoma Vasca. El líder de EA apoyaba su expectativa en la «caída previsible del PSOE y el avance de otras fuerzas», que romperían «el equilibrio inestable», en el que se mantenían nacionalistas y socialistas en el Ejecutivo Vasco. Se anunciaban buenos resultados para la coalición, a pesar de que la campaña era ingrata por culpa de la polarización de la misma en dos partidos ${ }^{136}$.

Los buenos resultados también los esperaba Azkarraga, al decir que «hubo una salida fulgurante cuando nacimos. En las elecciones europeas tuvimos una bajada que también concidió con la de otros partidos. Pero a partir de las últimas elecciones autonómicas hemos comenzado a subir y, en estos momentos, las encuestas dicen que en Euskadi somos el único partido que vamos en ascenso» ${ }^{137}$.

Garaikoetxea no sólo esperaba la ruptura de la Coalición entre PNV y PSOE por efecto de los resultados electorales, sino que éstos fuesen, además, el primer paso para instalar en los siguientes meses un Gobierno nacionalista en la Comunidad Autónoma Vasca. La alternativa estaba en EA-EUE ${ }^{138}$.

135 El Correo 28-V-93 (34). En Egin 23-V-93 (9) declaraciones de Albistur.

136 El Correo 28-V-93 (31).

137 El Correo 28-V-93 (34).

138 31-V-93 (24). En Egin 29-V-93 (14) Garaikoetxea dice: «Es el momento de un cambio, de una corriente de aire fresco que limpie Madrid de políticas económicas nefastas, y que 
Nuevamente, ya al final de la campaña, Garaikoetxea recalcó que aquellas elecciones eran «una especie de primarias para un posible cambio de Gobierno en Euskadi» ${ }^{139}$. Pero el papel de EA-EUE no se reducía al ámbito de la política autonómica vasca, sino que podía incidir de una manera decisoria en Las Cortes a través del Grupo Mixto, dada la fragmentación parlamentaria, que se esperaba. Si llegara el caso, se hablaría en Madrid con el Partido Socialista o el Partido Popular, «pero nunca a cambio de pagos en especie de interés partidista». En un contexto de fragmentación el voto a la coalición — añadió Azkarraga- cobraría «un nuevo valor a la hora de defender en Madrid los intereses económicos, políticos y sociales de Euskadi» ${ }^{140}$, y, mucho más, cuando no se estaba sujeto a la disciplina de ninguna internacional, como le ocurría al PNV ${ }^{141}$.

El corolario de tantas expectativas no era otro que el anuncio del «sí pero no» al estudio de una posible colaboración nacionalista en Madrid con el PNV, que exigía demasiadas cosas: La renuncia a la política de alianzas con los socialistas y su sustitución por una política de alianzas con los nacionalistas; cambio de la política económica; cambio de la política autonómica y aceptación de los enunciados básicos del programa de la Coalición, especialmente en materia social, porque, en coherencia con la honestidad y honradez proclamadas, «no vamos a traicionar jamás nuestro programa por una política de alianzas» ${ }^{142}$.

Dentro de este apartado cabe, por último, destacar dos cuestiones; por una lado, que la Coalición buscaba el apoyo de los sectores desencantados de Herri Batasuna para ampliar la base nacionalista, ya que «en HB hay sectores importantes que están hartos de dar su voto a una opción que después no los utiliza para nada, porque votar a HB es votar para que nada cambie. Hay que ampliar la base nacionalista, pero nunca lo haremos con HB mientras siga presa de la propia violencia. Pero nuestras puertas están abiertas a todas las personas de HB desencantadas» ${ }^{143}$; y por otro, que, en opinión del secretario general de EUE, la coalición con EA seguiría después de las elecciones y «en próximas confrontacio-

éstas sean como unas elecciones primarias que presagien el cambio que se puede producir en Euskadi el año que viene».

139 El Correo 2-VI-93 (28). En las mismas ideas de comenzar el cambio necesario en Euskadi insistió Baztarrika en El Correo 4-VI-93 (30).

140 El Correo 2-VI-93 (28).- Ver, también, Egin 24-V-93 (12) sobre el posible papel de la coalición de EA con otros «amigos de otros pueblos del Estado» de ser «el fiel de la balanza». «EA-EUA, dijo Garaikoetxea, será la llave del equilibrio entre el PSOE y el PP».

141 El Correo 24-V-93 (27).

142 El Correo 5-VI-93 (25).

143 El Correo 28-V-93 (34). 
nes electorales» ${ }^{144}$. El voto, que recogería EUE serviría para desplazar a Herri Batasuna y para frenar las ansias hegemónicas del Partido Nacionalista en Guipúzcoa ${ }^{145}$.

\section{B) La crítica de Partidos Políticos}

Así como la Coalición EA-EUE apenas fue mencionada en la campaña nacionalista del PNV, en la campaña de aquélla la bestia negra fue el Partido Nacionalista, ocupando un $47,15 \%$ de este apartado, lo que constituye un porcentaje muy elevado del espacio total, ya que la crítica a los Partidos Políticos superó la mitad de la campaña. Dada la coalición de Gobierno entre PNV y PSOE en Euskadi y la colaboración entre ambos en los órganos centrales, éste fue alcanzado en buena parte por los mismos dardos que el PNV.

A primera vista podría extrañar que tratándose de unas elecciones generales a Cortes se hablara más de la Coalición de Gobierno en el País Vasco, cosa que no se ponía en cuestión en las elecciones, que del posible Gobierno central en Madrid, y que en torno a ello se expusiera la principal descalificación del Partido Nacionalista. En realidad no debe extrañar que EA-EUE convirtiese la campaña de unas elecciones generales en una campaña más propia de elecciones autonómicas por dos razones principales: Primera, porque era el PNV el que quitaba el espacio electoral a la coalición, y, segunda, porque ésta creía que, 'faroladas' al margen, tenía poco que decir y, menos, hacer en la política general de España. Este es un problema grave que se manifiesta de la misma manera en el Partido Nacionalista y consiste en que los partidos nacionalistas vascos carecen de política de Estado, interpretando al mismo, simplemente, como al acaparador de poder y recursos ajenos, ante el que sólo cabe una política de extracción del máximo posible de su poder y recursos al amparo del particularismo, no generalizable por definición, que da una interpretación nacionalista del poder.

A ambos (PNV y PSOE) se debía el hecho de que España y el País Vasco estuvieran peor que nunca. «Nos han dejado casi tres millones y medio de parados, el $50 \%$ de los jóvenes vascos en situación de desempleo y la herencia de los astilleros desmantelados». La crisis del país, por culpa de la política gubernamental, era tan profunda que carecía de precedentes. La política seguida por el Gobierno vasco sólo había «beneficiado a los intereses financieros y a la especulación». Por ello se recor-

144 El Correo 5-VI-93 (25).
145 El Correo 23-V-93 (44). 
daba al electorado que no valía lamentarse y después votar de nuevo al Partido Nacionalista o al PSOE ${ }^{146}$. El PNV era responsable de la política económica de Solchaga por haberla apoyado como de normas restrictivas, tipo Ley Corcuera, por la misma razón ${ }^{147}$. Tanto apoyo del PNV al Partido Socialista en el Congreso de los Diputados sólo había servido para marginar «a Euskadi a la hora de otorgar las inversiones en política de desarrollo» ${ }^{148}$.

En Guipúzcoa el peneuvista Eli Galdos simbolizaba la chapuza de la autovía, que supuso «el despilfarro de 8.000 millones de pesetas más para los guipuzcoanos y el brindis con champán de la mesa nacional de HB» ${ }^{149}$.

La aprobación del proyecto de ley de creación del Banco Público Vasco era una caída en «tentaciones electoralistas» por parte del Gobierno Vasco.

El líder de EA insistió en que en aquellas elecciones generales a Cortes se ponía «muy a prueba en la Comunidad Autónoma la fórmula de gobierno, porque cuando parecían inmunes a todas las contradicciones se percibe que en la sociedad hay una reacción ante la cadena de absurdos que esta fórmula de gobierno está produciendo» ${ }^{150}$. Resultaba «curioso que proyectos como el Banco Público Vasco o el incentivo fiscal a las empresas salgan adelante en el Parlamento vasco por el apoyo de EA y EUE, cuando los socios del PNV, los socialistas, votan en contra» ${ }^{151}$. Era «muy grave que un presidente nacionalista — José Antonio Ardanza(mantuviese) en el Gobierno Vasco a la mitad de un ejecutivo que le da la proa en una cuestión» como la del Banco Público Vasco ${ }^{152}$.

Los intentos del PNV «por desmarcarse a última hora del PSOE, después de haber mantenido una sintonía perfecta en Madrid y en Euskadi durante ocho años, no engañan a nadie» ${ }^{153}$.

De una manera muy radical se afirmó que «el PSOE no ha tenido votos más baratos que los del PNV, que en la última legislatura se ha comportado como el auténtico manporrero de los socialistas. Lleva razón Emilio Olabarría cuando dice que el PSE es el gendarme del Estado en Euskadi, y Mario Onaindía el sargento chusquero de esos gendarmes, pero se olvida que eso es así porque el PNV lo ha querido» ${ }^{154}$.

\footnotetext{
146 El Correo 23-V-93 (44).

147 El Correo 30-V-93 (41).

148 El Correo 30-V-93 (41).

149 El Correo 4-VI-93 (30).

150 El Correo 28-V-93 (31).

151 El Correo 28-V-93 (34). Son palabras de Azkarraga.

152 El Correo 30-V-93 (41).

153 El Correo 30-V-93 (41).

154 El Correo 31-V-93 (24).
} 
En materia autonómica eran responsables de que en seis años no se hubiese transferido ni una sola competencia. Por otra parte, el acuerdo sobre las 54 transferencias pendientes se interpretaba como una cuestión electoral, «absolutamente falso», que se ponía de manifiesto con las discrepancias surgidas entre nacionalistas y socialistas sobre el Banco Público Vasco. El fracaso autonómico se manifestaba, además, en la interpretación de los mecanismos de autogobierno puestos ya en marcha, como ocurría con el Concierto Económico, y en las leyes de base, que desnaturalizaban e, incluso, anulaban, «competencias reconocidas en el Estatuto» ${ }^{155}$.

La crítica alcanzaba a los Gobiernos y a la Administración, también, por su incapacidad para «unificar las energías entre los jóvenes», dado el altísimo porcentaje de jóvenes en situación de paro ${ }^{156}$.

La honestidad, le regeneración y la renovación, que la coalición EAEUE prometía en su actuación política, eran el positivo de la corrupción, que denunciaban en otros partidos, especialmente en el PNV. La selección con criterios partidistas del personal de la Administración vasca y el mantenimiento de criterios tolerantes en el desvío de dinero público para la financiación de los partidos fueron denunciados por Joseba Azkarraga. Hablando en concreto sobre el Consejero de Interior, Atutxa, manifestó: «Me parece que se está equivocando en el propio reclutamiento de la Ertzaintza, porque se sigue reclutando en función de que sea hijo de un afiliado o porque su madre hace pinchos de tortilla en el batzoki de Lekeitio, no por su preparación. Está utilizando la Administración de forma negativa. Aunque también ha tenido aciertos, como la persecución del cobro del "impuesto revolucionario" ${ }^{157}$. Y, sobre la pregunta de si conocía a políticos corruptos, respondió: «Conozco a políticos sobre los que se mantiene la sospecha de corrupción. Ahí tenemos a Filesa o el caso de Max Center en Barakaldo o los chanchullos de las máquinas tragaperras. Pero el auténtico problema surge cuando políticos como Arzalluz dicen que no es lo mismo corromperse para el beneficio de uno mismo que corromperse para la financiación de su partido. Es un planteamiento gravísimo... Está planteando algo importante: saber hasta qué punto hay partidos que se han corrompido para hacer una campaña electoral del nivel

155 El Correo 25-V-93 (28). Azkarraga manifestó: «Está absolutamente paralizada (la autonomía) y es que este estatuto se parece al aprobado en 1979 lo mismo que un huevo a una castaña.Durante los últimos seis años sólo se ha producido la transferencia de Viveros y Plantas» (El Correo 28-V-93, 34). En El Correo 30-V-93 (41) Garaikoetxea dice que «toman por tontos a los ciudadanos cuando anuncian que, justo ahora, se van a desbloquear 55 transferencias que han estado paralizadas durante ocho años» y «en la primera cuestión en que se pone a prueba la autenticidad de estos acuerdos, con el Banco Público Vasco, salta el escándalo».

156 El Correo 26-V-93 (29).

157 El Correo 28-V-93 (34). 
que se está haciendo. No estoy acusando de nada al PNV, porque es el PNV el que dice públicamente que eso es menos delito. Nosotros, por ejemplo, dentro de nuestro programa electoral planteamos terminar con la inmunidad parlamentaria, porque históricamente se ha utilizado como una especie de salvaguarda del político ante el poder, pero en los últimos años se ha empleado para escaparse de la Justicia, para tapar corruptelas que nada tienen que ver con la práctica de la política» ${ }^{158}$.

El PNV era responsable, incluso, de la aparición de un partido antinacionalista como el de Unidad Alavesa. Se trataba de un proceso «sustentado por algún preboste del PNV». Azkarraga comentó: «Cuando hace unos años se discutía en Alava la LTH, ya se hablaba del agravio que suponía para Alava. Entonces se estaban poniendo los cimientos de todo esto y por eso UA es la hija del PNV. De todas formas, espero que sea algo temporal y que el nacionalismo vuelva a recuperar su fuerza» ${ }^{159}$. Tanto el PNV como Herri Batasuna eran culpables de la división del nacionalismo vasco, que llevaba al «absurdo» de que existiese en el País Vasco «una mayoría nacionalista en las convicciones y en el voto, y que luego esa mayoría no se (articulase) para decidir qué queremos hacer por Euskadi». La pretensión del PNV de monopolización del nacionalismo y la violencia de ETA y HB explicaban el fenómeno ${ }^{160}$.

En la crítica de la bipolarización de la campaña, que también se hizo desde EA-EUA, se comentó que el más afectado era el PNV, porque la política que le había dado buena parte de los votos, la política ambigua, se veía perjudicada con el ascenso del Partido Popular ${ }^{161}$.

La posibilidad de un pacto de Gobierno del PNV con el PSOE o PP se presentaba como un intento de los grandes partidos de aparentar un apoyo del nacionalismo vasco, cuando lo único que buscaban era el apoyo de los cinco diputados nacionalistas ${ }^{162}$. El Partido Nacionalista habría llegado, según Aulestia, a una situación de ansiedad por sumar sus votos a alguien, que podría terminar en «abaratar el precio que debe Madrid a Euskadi y su debilitamiento respecto del poder central» ${ }^{163}$.

El resumen de la crítica al PNV no lo hicieron Albistur al pedir «el voto crítico a los que han gobernado desde la arrogancia, con la creencia de que este País es suyo» ${ }^{164}$, ni Gurrutxaga al negar la posibilidad de colaboración

\footnotetext{
158 Ibídem.

159 El Correo 28-V-93 (34).

160 Deia 1-VI-93 (7).

161 Ver El Correo 2-VI-93 (28).

162 El Correo 5-VI-93 (25).

163 El Correo 28-V-93 (31).

164 El Correo 4-VI-93 (30).
} 
con el PNV, mientras no reconociese que el nacionalismo era plural y que, por tanto, no podía monopolizar el nacionalismo vasco ${ }^{165}$. Más bien, la síntesis está en las palabras de este último orador, cuando dijo: «La única ideología que tiene el PNV no es el nacionalismo, sino la del poder» ${ }^{166}$.

Como era de esperar, el segundo Partido más criticado fue el Partido Socialista (PSOE-EE) con un $41,84 \%$ de este apartado. Esto hace que la mitad de la campaña de la coalición EA-EUE, poco más o menos, la acaparasen los dos partidos más importantes del País Vasco. La lucha por el poder llevaba a la censura del uso del poder.

Como ya se ha advertido, en buena medida la censura fue común a ambos partidos. Ahora se trata de destacar lo que hubo de específico en la crítica al Partido Socialista. Así, en materia estatutaria el PSOE era el responsable de que se hubiese roto el pacto de voluntades entre nacionalistas y no nacionalistas, que era el Estatuto, así como también de su paralización. «Esto demuestra la nula voluntad autonómica del Gobierno y la falta de capacidad política para llegar a acuerdos entre el Estado y la comunidad autónoma» ${ }^{167}$.

Se destacaba que el PSOE imponía al final siempre su ley y tácitamente se decía que el gran beneficiario de los entendimientos entre socialistas y nacionalistas era el Partido Socialista ${ }^{168}$.

Aulestia se refirió a la petición socialista del voto, que se basaba en la presentación del PSOE como garante del mantenimiento de las industrias en Bizkaia, y destacó la falta de responsabilidad con que se había comportado sobre aquel tema. La política económica socialista en ningún momento, manifestó Albistur, había «intentado evitar la desindustrialización del País Vasco» ${ }^{169}$.

La crítica en materia económica insistía en el abandono y en el olvido en el que el Gobierno central tenía a la economía y a la industria vasca. El Partido Socialista rechazaba las medidas de incentivos a la inversión, que «hace años, cuando se tomaban estas medidas ni Franco se atrevía a discutirlas y ahora, los que gobiernan con el PNV están impugnándolas» ${ }^{170}$. Los años de Gobierno socialista habían sido desastrosos para el País Vasco por haber supuesto «con el apoyo sistemático del PNV» un desmante-

165 5-VI-93 (25). EA anunció acciones contra el hecho de que el PNV hubiese utilizado la figura institucional del Lehendakari para solicitar el voto para el PNV (El Correo 5-VI-93, 25).

166 Egin 30-V-93 (16).

167 El Correo 21-V-93 (29).

168 Ver El Correo 30-V-93 (41).

169 El Correo 23-V-93 (44).

170 El Correo 24-V-93 (27). 
lamiento «industrial brutal, que ha condenado al desempleo a un importante número de población» ${ }^{171}$.

Euskadiko Ezkerra, integrada en el Partido Socialista, fue acusada de haber servido de «guía comanche para que la caballería del PSOE pudiera entrar en el país» ${ }^{172}$. Sobre ella y sus hombres recayeron más críticas. De Bandrés se dijo que le tenía que producir «vergüenza haber faltado a su palabra ya que, cuando estaba en EE, aseguró muchas veces que mientras él fuera presidente el partido no entraría en el PSOE». El voto a los socialistas era votar «el encarcelamiento de los objetores insumisos», de ahí que se dudara de que los antiguos votantes de EE votaran al Partido Socialista para que 8.000 jóvenes insumisos vascos fuesen encarcelados. Por cierto, como Mario Onaindía también era objetor, estaba «haciendo su prestación social sustitutoria en el PSOE» ${ }^{173}$.

La búsqueda de los votos de lo antiguos simpatizantes de Euskadiko Ezkerra llevó a que sus exmiembros trataran de desprestigiar a políticos como Bandrés y Onaindía y afirmar que al PSOE sólo se habían ido unas siglas y unos candidatos. Por otra parte, el Partido Socialista aparentaba ser una izquierda política, que en realidad no existía. Su estrategia de campaña había sustituido el debate político democrático por la estrategia del miedo ${ }^{174}$.

Aunque en principio pudiera pensarse que, dado el interés expresamente manifestado de captar parte, al menos, del electorado de Herri Batasuna, la Coalición EA-EUE se habría dirigido críticamente contra ella, sin embargo, no fue así, ni en sentido positivo ni negativo. No llegó al $10 \%$ de este apartado la censura de Herri Batasuna.

Se lamentó, exageradamente, por cierto, que su ausencia del Parlamento hubiese permitido aprobar la Ley Corcuera o el Decretazo. Así mismo, se lamentó que desde el mundo de HB se introdujeran en la campaña perturbaciones, que habían terminado en las «actitudes intimidatorias» manifestadas en los carteles firmados por Jarrai. EA-EUE, que denunciaba a HB por ser rehén de la violencia, se consideraba la única fuerza política, que podía desplazar a HB en Guipúzcoa ${ }^{175}$. «Frente a esos que utilizan los muertos como propaganda electoral, decimos que ya bas-

171 El Correo 27-V-93 (35).

172 Ibídem.

173 El Correo 30-V-93 (41). De Bandrés se dijo en otro momento: «Me da pena Juan María Bandrés. Da la impresión de que en lugar de hacer pública una carta para pedir el voto para el PSOE, lo que ha hecho es pedir perdón. Parece que se ha arrepentido de apuntarse al último vagón de ese tren, aunque no se atreva a decirlo» (El Correo 31-V-93, 24).

174 Ver El Correo l-VI-93 (33); 31-V-93 (24).

175 Ver El Correo 23-V-93 (44); 28-V-93 (31); 4-VI-93 (30). 
ta, que ese camino no nos ha traído a todos los vascos más que muerte y divisiones», dijo Koldo Martínez ${ }^{176}$.

Las referencias al Partido Popular fueron insignificantes y tocaron cuestiones como la bipolarización de la campaña o los posibles acuerdos con el Partido Nacionalista para formar Gobierno ${ }^{177}$.

\section{La campaña de Herri Batasuna}

\section{Datos básicos}

A diferencia de lo que ocurrió en los demás partidos nacionalistas en la campaña de Herri Batasuna ocupó más espacio la exposición de la imagen o definición de Partido que la crítica, aunque la diferencia fue reducida. La imagen ocupó un 52,36\%, mientras que la censura a los Partidos Políticos ocupó el 47,63\%.

Siguiendo con el modelo de distribución de contenidos de la definición de Partido o Agrupación o Coalición, se observa que en la campaña de HB se produjeron notables alteraciones. La exposición propagandística de contenidos o motivos esenciales a la ideología nacionalista ocupó el $87,80 \%$ de este apartado, destacando hasta alcanzar la cota del $83 \%$ de la imagen la cuestión de la independencia y las libertades nacionales. El segundo de los puntos, el de cuestiones programáticas y otras ideologías, sólo ocupó el 10,16\% con mínimas apreciaciones en cuestiones tales como la participación parlamentaria, la corrupción, la reinserción o el indulto a Amedo. En realidad no hubo propuestas concretas para resolver problemas. El tercer punto, el de las cuestiones de Gobierno, prácticamente no existió, lo que es absolutamente lógico, ya que el desprecio de la política diaria es esencial a un partido radical del todo o nada. Sólo tuvo 1,8\% de espacio, donde se expresó una cierta preferencia por un triunfo del PSOE.

La distribución de la crítica a los Partidos Políticos fue la siguiente: Partido Nacionalista Vasco, 46,40\%; Partido Socialista, 21,83\%; Partido Popular, 12,15\%; Unidad Alavesa, 10,91\%; y, por último, Euzko Alkartasuna, $8,68 \%$.

La participación de los actores políticos arrojó estos resultados: Idígoras, 40,18\%; Usategi 17,15\%; J. Goirizelaia, 11,28\%; J. Ruiz de Pinedo, 10,38\%. El resto se repartió con cantidades insignificantes desde el 5\% hasta el $1 \%$ entre Floren Aoiz, Iruin, B.Garmendia, Gorostiaga, Zabaleta y Rafa Díez.

\footnotetext{
176 Egin 25-V-93 (16).

177 Ver, por ejemplo, El Correo 5-VI-93 (25).
} 


\section{Desarrollo de la campaña}

A) La imagen de Partido

1. La ideología nacionalista

Desde el primer día HB hizo un constante llamamiento a la participación en las elecciones — porque «nos jugamos el porvenir»-, y pidió el regreso del voto de aquéllos que se habían ido «por las más diversas circunstancias» ${ }^{178}$, prometiendo hablar durante la campaña de autodeterminación, decretazo, corrupción, negociación y paz, industrialización, pensiones y descentralización. Habló de todo ello desde un punto de vista estríctamente nacionalista, cuya ideología en sentido estricto defiende la independencia nacional como fuente y origen de la solución de todos los problemas de la comunidad nacional.

Según esto, la superación de la crisis económica y el posterior desarrollo económico de Euskadi, que se encontraba en «situación de emergencia nacional», precisamente, por motivos económicos, estaban vinculados a la progresiva ruptura de «lazos con el Gobierno español». Más aún, «no hay futuro económico, que no esté vinculado a la recuperación de nuestra soberanía», manifestó el primer candidato al Congreso por Alava, Iñaki Usategi. Lo mismo manifestó Rafa Díez al defender que sin soberanía política para intervenir en la economía aumentaría el deterioro económico e industrial del País Vasco.

En este sentido ha de entenderse la afirmación de que el voto a Herri Batasuna era «un tesoro para todos los trabajadores», ya que era el apoyo no sólo para mantener las empresas, «sino para sacar la economía adelante».

En la presentación del voto a HB como voto trabajador hay que situar el interés por recuperar la utopía socialista «porque si no, la van a recuperar los de IU desde Madrid».

El mensaje de HB en relación con la paz iba a ser de «mano tendida» a favor de la negociación como camino para la paz. Pero este camino pasaba «por un nuevo marco de relaciones con el Estado español»y, también, con Europa, a donde había que ir sin dependencia del Gobierno de Madrid $^{179}$.

178 El Correo 30-V-93 (41). En Egin 23-V-93 (11) hay denuncias contra el PNV, acusado de enviar cartas a militantes y simpatizantes de HB animándoles a la abstención. El lema de HB era que «abstenerse es dar carta blanca al Estado» (Egin 25-V-93, 11). Ver, también, Egin 26-V-93 (10 y 11$)$ y $27-\mathrm{V}-93$ (14 y 15$)$.

179 Ver para todo esto: El Correo 21-V-93 (30); 23-V-93 (44) y 26-V-93 (29). En Egin 3-VI-93 (14) se atribuye a Patxi Zabaleta lo siguiente: «Un pueblo es pueblo en tanto en cuanto tiene el derecho de autodeterminación» $\mathrm{y}$ «la libertad (independencia) de este pueblo 
En una nota enviada a los medios de comunicación Iñaki Ruiz de Pinedo desarrollaba el sentido de las nuevas relaciones entre Estado y comunidad Autónoma, que debía abordarse en próximos años. La nota reconocía la inutilidad del sistema político vigente, que después de varios años de Estatuto, no había permitido «avances para nuestro pueblo en la consecución de auténticas cotas de soberanía política». Por el contrario, en el aspecto económico se habían dado «pasos atrás». El nuevo sistema debía incluir «el reconocimiento del derecho de autodeterminación, si se quiere encontrar una solución de consenso y definitiva al conflicto político que hoy vive nuestro pueblo». Además, como «no hay solución posible sin poner fin a la división territorial de nuestro pueblo, ya que es uno de los hechos más negativos que estamos sufriendo», era objetivo de su formación la consecución de un proyecto, que supusiera «la reunificación de los territorios vascos, hoy, separados por constituciones y estatutos impuestos» ${ }^{180}$.

El derecho de autodeterminación — «nadie que sea demócrata puede negarnos el derecho a la autodeterminación $»^{\gg 1}$ — debía ser reconocido a los vascos como se había reconocido a naciones europeas como Lituania, Chequia o Eslovaquia. «¿Acaso no es democrático — dijo Jone Goirizelaia - preguntar directamente a los propios ciudadanos y ciudadanas qué es lo que quieren para su país?» La utilización de la autodeterminación, una vez reconocido el derecho, que HB defendería sería para la independencia. «Cuando arranquemos del Estado español ese derecho lucharemos para que la opción que elija este pueblo sea la independencia, porque no somos ni españoles ni franceses, ni queremos serlo». Y a continuación se establecía de acuerdo con el más puro nacionalismo que la paz de Euskal Herria, bien fundamental, llegaría a través de «la paz de la justicia, la libertad, la paz de la autodeterminación». Mientras tanto, el diálogo y la negociación política entre ETA y el Estado, en el que debían estar presentes también los partidos políticos y todos los agentes sociales, constituían el instrumento de la paz, una paz sin vencedores ni vencidos. Herri Batasuna se comprometía a «obligar al Estado español a rectificar y a abrir el camino de la negociación». El voto a HB serviría para demostrar que «Euskal Herria no se rinde y continúa luchando por sus derechos» ${ }^{182}$.

es imprescindible para defender nuestro tejido industrial, los recursos naturales, nuestra ecología e incluso para ser solidarios». Herri Batasuna no respondió a la petición de no usar el terrorismo como arma arrojadiza contra los Partidos Políticos durante la campaña (El Correo 22-V-93, 12). En El Correo 26-V-93 (29) I. Usategi repite ante la planta de Tubacex en Llodio que «sin la recuperación de la soberanía vasca» no había fórmula para reactivar la economía. Ver Egin 26-V-93 (12).

180 El Correo 24-V-93 (26).

181 Egin 30-V-93 (10).

182 El Correo 29-V-93 (31). 
En la mesa redonda organizada por Egin-Irratia, Karmelo Landa expresó la posición de Herri Batasuna sobre la autodeterminación en términos claros, que repetían el planteamiento de la campaña y exponían una tesis netamente nacionalista: «El Estatuto de Gernika es hijo natural de la Constitución española y, por lo tanto, no hay posibilidad de ejercer el derecho de autodeterminación. Nos parece una cuestión crucial conquistar este derecho y no estamos en democracia porque a los vascos no se nos reconoce la posibilidad de ejercitarlo, de ser soberanos, de formar un estado propio y de salir de esta tremenda crisis en la que nos está metiendo Madrid y la supeditación del PNV y otros partidos de aquí» ${ }^{183}$.

La paz sólo podría alcanzarse al término de la violencia estatal y de las injusticias contra el Pueblo vasco. La paz, «justa y verdadera», llegaría cuando se detuviese «la maquinaria violenta del Estado, que es la causa de que existan dos violencias enfrentadas». Herri Batasuna era la alternativa a un sistema político, el que definía las vigentes relaciones entre Estado español y Euskadi, «la democracia española», que permitía «la corrupción, el secuestro permanente de la voluntad popular, el enriquecimiento de unos pocos y la negación de los derechos de los pueblos». Ante la democracia española la «tarea prioritaria» de la izquierda debía ser la defensa de las libertades nacionales. En nombre de estos planteamientos Floren Aoiz pidió «la rebeldía y la lucha y también el voto» por ser «instrumentos útiles contra la injusticia y para que Euskal Herria sea libre», y defendió la necesidad de obtener el reconocimiento del derecho de autodeterminación para que fuese la sociedad vasca quien decidiese y «no el poder de Madrid» ${ }^{184}$.

En Alava era el proyecto político de Herri Batasuna el único capaz de «frenar a la derecha españolista» ${ }^{185}$.

En una entrevista realizada por El Correo a Jon Idígoras, éste pasó revista a la mayor parte de los temas tratados en la campaña. Era una forma más reposada de enfrentarse con los mismos problemas. Las respuestas eran en algún caso más clarificadoras del fenómeno nacionalista. Sobre la desaparición de la violencia durante la campaña el entrevistador preguntaba si ello se debía a que los defensores dentro de HB de que la violencia debía pasar a un segundo término, al menos, en elecciones habían conseguido imponer sus tesis. Jon Idígoras respondió: «El planteamiento es incorrecto, porque en Herri Batasuna no nos hemos planteado que la violencia esté en primer o en segundo lugar. Cuando nos hemos planteado el tema de las violencias, pluralizo a propósito, entendemos

\footnotetext{
183 Egin 28-V-93 (14).

184 El Correo 22-V-93 (33). Sobre la violencia del Estado, la huelga de hambre de los presos por la soberanía y la autodeterminación, ver, también, Egin 25-V-93 (19) y 24-V-93 (16).

185 El Correo 23-V-93 (44).
} 
que no sólo debe pasar a segundo plano, sino que deberían desaparecer. Uno de los ejes de nuestro programa político es precisamente superar cualquier expresión de violencia que se dé en este país. Ese objetivo está en relación directa con las medidas políticas que se tienen que adoptar por el Gobierno del Estado para crear las condiciones favorables. En primer lugar, una toma de contacto con la organización ETA en la búsqueda de acuerdos y compromisos y la creación del clima necesario para que este prospere. Está claro que estoy hablando de negociación política en términos concretos. Hoy no se entiende una desaparición de la violencia sin que existan medidas concretas como un reconocimiento por parte del Gobierno del derecho de autodeterminación. En cuanto se den determinadas condiciones, creemos que las violencias van a desaparecer como la gripe» ${ }^{186}$. Idígoras insistió en que la pluralidad de violencias no era una invención teórica de KAS. «Esto está en la percepción de cualquier ciudadano de este país. Acabamos de asistir a los juicios por los asesinatos de Brouard y de Muguruza; estamos viendo el chantaje y las amenazas que desde Amedo y su entorno se están haciendo a instancias superiores del Estado. Además, se conculcan diariamente un montón de derechos individuales y colectivos. La verdad es que no puede haber una expresión más clara de la violencia del Estado» ${ }^{187}$.

Se negaba en esta entrevista que el ejercicio de la autodeterminación pudiese llevar a la guerra, argumentando, de una manera harto superficial, que en Euskadi no existía un problema de etnias, que históricamente hubiese generado fobias interraciales.

En cuanto a los posibles efectos políticos de la inactividad de ETA durante la campaña electoral, Idígoras manifestó que no había «empujado al estado a adoptar posturas más flexibles. Esta situación, vamos a llamarla de calma chicha, no ha influido en el Estado para buscar un diálogo. Todavía hace poco que ETA hablaba de que está en disposición de ofrecer las treguas que sean necesarias en el camino de buscar el diálogo y la negociación. La verdad es que por parte del Estado no hay ninguna respuesta positiva que yo conozca. Es más, lo que vemos es un endurecimiento, al menos verbal, no sólo del Estado sino de la derecha española. Entienden que eso les da votos en España. Esperemos que cuando termine la resaca del 6 de junio se dé paso a una reflexión más profunda» ${ }^{188}$.

Una de las respuestas más substanciales, por lo clarificadora, es la que dio Idígoras como explicación del slogan tan repetido en la campaña

186 El Correo 29-V-93 (35). En Egin 4-VI-93 (12 y 13) aparece otra entrevista a Idígoras en la que se manifiestan las mismas ideas recogidas a lo largo del trabajo.

187 Ibídem.

188 Ibídem. 
«contra el paro soberanía». En ella se concentran varios elementos esenciales al nacionalismo: El carácter mítico; la ausencia y rechazo del realismo, no obstante la conciencia sobre algunos puntos objetivos; la inexistencia de programas de praxis política, y la simplificación manifestada en la propuesta final de que la nación libre es la solución de todos los problemas. «En sí mismo - dijo Idígoras - es efectivamente un slogan bonito que no quiere decir nada, pero para que se adopten las medidas necesarias de choque contra la crisis, las instituciones vascas tienen que tener en sus manos verdaderos instrumentos de poder político. No presentamos un programa electoral porque la resolución de los problemas requiere un progrma político de aplicación diaria que llevamos defendiendo todo el año. El problema es estructural y en buena parte por culpa del proceso de integración europea y el monetarismo. Nosotros encerramos el problema en tres soluciones concatenadas: medidas de defensa para la economía, el tema de la paz y el derecho a la autodeterminación» ${ }^{189}$. El mismo bagaje ideológico se esconde en la respuesta al tipo de votante de HB. «Lo cierto es que HB tiene el porcentaje más alto de fidelidad de voto. Y es así porque en este momento una gran parte del electorado no ve una salida. Este electorado piensa que hay que mantener una actitud de rebeldía y de compromiso político para obligar a determinados cambios en profundidad» ${ }^{190}$.

La escenificación de este mixtura de elementos, paro, crisis económica, exaltación de ETA y de sus presos, críticas a la corrupción y a la tortura, petición de voto y proclamación, que no demostración, de que la solución estaba en recorrer el largo camino hacia el proyecto de soberanía de Euskadi, se produjo en el mitín celebrado en el velódromo de Anoeta, que, por primera vez, Herri Batasuna no consiguió llenar ${ }^{191}$.

En resumen, Herri Batasuna encarnaba la izquierda, que necesitaba Euskadi, la izquierda capaz de «organizar la respuesta social que requiere la salvaje ofensiva económica lanzada por el capitalismo contra el pueblo vasco», que, además, era democrática, porque realizaba el ideal de participación universal (Herri Batasuna era «labor de todas y de todos») en defensa de «los intereses de todos y de todas» ${ }^{192}$. Y, lo más importante, Herri Batasuna defendía «un proyecto nacional» frente al «provincianismo de EA y el vascongadismo del PNV». El resultado sería el éxito electoral y especialmente, el liderazgo en Guipúzcoa a pesar de las coaliciones de los demás Partidos políticos ${ }^{193}$.

\footnotetext{
189 Ibídem.

190 Ibídem.

191 Ver El Correo 30-V-93 (41) y, especialmente, Egin 30-V-93 (10 y 11).

192 El Correo 1-VI-93 (35).

193 El Correo 2-VI-93 (29).
} 
En esta materia la campaña terminó como comenzó, es decir, pidiendo la participación electoral y el voto con la añadidura de la necesidad de agrupar todas las fuerzas de izquierda para hacer frente a la situación de Euskadi. La tarea más importante del momento consistía en «consolidar HB para evitar dividir o dispersar el voto», ya que la abstención siempre había sido «aprovechada por las fuerzas más reaccionarias y por los partidos que en los últimos 14 años no han hecho más que conducirnos a la ruina». Para ello Idígoras pidió a los delegados de LAB que transmitiesen tal «necesidad a todos los compañeros de otros partidos políticos $\mathrm{u}$ otras centrales sindicales, tanto en sus centros de trabajo como en la calle» para «sacar a esta sociedad de la indiferencia y hacer del ciudadano y de la ciudadana un elemento activo de esta sociedad». Si se quería hacer frente a la situación laboral y económica, había que reclamar «instrumentos de soberanía política para poder tener en nuestras manos la planificación y la reindustrialización» ${ }^{194}$.

No parece que estaba muy clara la unidad de la izquierda, ya que Idígoras en su última intervención, después de recordar la necesidad de aunar el mayor número de fuerzas en torno a «una alternativa y programa de izquierdas» como el de Herri Batasuna (que dicho sea de paso, nunca se explicitó en qué consistía), manifestó que, aunque se habían cometido muchos errores, era hora ya de «arreglarnos y buscar soluciones, porque son más las cosas que nos unen que las que nos separan». En la jornada electoral había que «ejercer de vascos» diciendo que «esto no es España». La libre y pacífica convivencia con los españoles dependía del «reconocimiento, por parte de éstos, del derecho a la autodeterminación, instrumento que nos puede llevar a la soberanía» ${ }^{195}$. Herri Batasuna se oponía a que Euskal Herria se convirtiese en «un cortijo de los españoles y (a) que las instituciones vascas (fuesen) unos meros consulados de Madrid»196. Había que votar a HB, porque «necesitamos paz, soberanía y libertad» ${ }^{197}$.

\section{Cuestiones programáticas y otras ideologías}

Herri Batasuna no comunicó al electorado ningún plan de políticas específicas para actuar desde el poder. Ni podía hacerlo, dado el planteamiento exclusivamente nacionalista que la coalición radical hizo de la

194 El Correo 4-VI-93- (31).

195 El Correo 5-VI-93 (25). En Egin 4-VI-93 (13) Idígoras manifiesta: «Ahí todo el que se sienta de izquierdas debe hacer un esfuerzo y apoyarnos con su voto. La izquierda no puede dispersar el voto por pequeñas diferencias».

196 Egin 30-V-93 (10).

197 Egin 2-VI-93 (16). 
campaña. Sólo se encuentran en sus intervenciones cuestiones relacionadas con su actitud política general como son la cuestión del indulto a Amedo, la reinserción, la corrupción y la participación parlamentaria, que no son otra cosa que una ocasión para censurar a los Partidos pro sistema. Las afirmaciones solemnes de que HB era el partido de la izquierda, que promovía la utopía socialista, se quedaron en la solemnidad sin ningún tipo de concreción ${ }^{198}$. Es cierto, sin embargo, que HB propuso medidas de muy diverso signo, tanto a corto plazo como a medio plazo, pero todas ellas estaban supeditadas a la previa transformación de las relaciones políticas con España, concretadas en la autodeterminación y en la independencia. Según HB la superación de la crisis económica requería la unidad de acción de todos los agentes sociales desde los partidos políticos hasta los movimientos populares; la retención del dinero, que anualmente se llevaba Madrid; la transferencia de la Seguridad Social, de todas las infraestructuras, de las empresas públicas y la creación de un sector público vasco. Pero «todo lo que hemos señalado - manifestó Idígoras - no es posible hacerlo dentro de las cotas de poder político que tienen las instituciones autonómicas hoy en día. A través de estas instituciones no es posible adoptar estas medidas, porque no hay instrumentos para ello. Hay que constatar una vez más que quien reparte el juego en este terreno es Madrid y los vascos estamos al capricho de sus decisiones. Precisamente por eso pedimos un cambio profundo de nuestras relaciones con el Estado. Necesitamos cotas de poder político suficientes para poder administrar, diseñar y buscar la inversión. Cuando hablamos de la autodeterminación y la necesidad de un Estado vasco estamos hablando de todo ello. No son reclamaciones gratuitas» ${ }^{199}$.

198 En un artículo titulado «Una propuesta económica desde la izquierda» de Jon Iñaki Usategui (El Correo 2-V-93, 39) se recoge el supuesto programa de HB sobre política económica con los planteamientos de fondo, que se han visto en el apartado anterior. En él se escribe que «desde Herri Batasuna, con el Plan de Emergencia de seis propuestas hemos exigido el replanteamiento de los flujos financieros con el Estado español o el de las relaciones vascas con Europa. Otras aportaciones al debate han sido el Instituto de Empleo propio, la Seguridad Social, la política presupuestaria como instrumento de redistribución de riqueza, el combate al fraude fiscal o la necesidad inaplazable de un diseño territorial para nuestra tierra. Las propuestas son técnicamente fundamentadas, orientadas para dar a la crisis económica una salida progresista y de izquierdas... Nuestro futuro económico aparace cada vez más vinculado a la recuperación de la soberanía vasca, de forma que no es posible analizar con seriedad los graves problemas económicos sin poner en cuestión nuestras relaciones con España, con un ordenamiento jurídico que niega amenazadoramente a los territorios vascos esa capacidad real de decisión, que sólo puede lograrse a través del ejercicio del derecho de autodeterminación».

199 Egin 4-VI-93 (13). Las mismas ideas aparecen en Deia 26-V-93 (6) en una entrevista a Begoña Garmendia, candidata de HB al Congreso. 
Sobre Amedo se dijo que estaba intentando arreglar su futuro en negociaciones con las instituciones del Estado, pero se rechazó la misma posibilidad de que el Gobierno estudiase la aplicación del indulto. «Pone los pelos de punta - manifestó Usategi- ver cómo han utilizado los aparatos del Estado para golpear sangrientamente al pueblo vasco. Solamente les faltaría que, igual que Garzón, hubiesen entrado (Amedo y Domínguez) en las listas electorales del PSOE» ${ }^{200}$.

La reinserción fue lógicamente interpretada desde la óptica de la legitimidad de la ideología, bajo cuyo amparo se utilizó la violencia. Pero el argumento utilizado es falso, porque la reinserción no exigía renuncia a ideologías políticas, lo cual habría sido anticonstitucional, sino a la violencia. «A mi — dijo Idígoras - la reinserción me parece una medida humillante e ignominiosa para cualquier preso político. Que puedan acogerse a beneficios por razones personales, porque han quebrado física o psicológicamente, esa es otra cuestión. Pero tal como está concebida la reinserción, como renuncia a todas las posiciones políticas que les llevaron a utilizar la violencia, me parece una humillación. El tema de los presos tiene que entrar de lleno en el plan de diálogo con el Estado, porque también son una cuestión de Estado» ${ }^{201}$.

Dada la corrupción, que venían practicando todos los partidos políticos, Herri Batasuna denunciaba el hecho de que todos «nos estamos acostumbrando a vivir un modo de hacer política donde comienzan a pu-

200 El Correo 21-V-93 (13).

201 El Correo 29-V-93 (35). La muerte de Pello Mariñelarena en la prisión de Fresnes fue interpretada por José María Olarra «como el noveno preso político asesinado en las prisiones por defender un proyecto, que es la libertad de este país. Ha llegado la hora de decir que basta y parar esto. Nosotros presentamos una alternativa de cambio, de solidaridad con estos gudaris, que diga que Euskadi quiere ser independiente, y que represente un voto abertzale y sobre todo anti-Estado español y anti-Estado francés» (Egin 23-V-93, 13). En página 14 del mismo día se dice que esta muerte ha desatado la ira de una población de manera que «Sakana (es) un valle en pie de guerra». Egin 31-V-93 (16) recoge las intervenciones en el homenaje a los presos en huelga de hambre, en las que se trata de manifestar la identificación de los presos con el análisis y proyecto político de HB: «La política de exterminio que contra ellos se aplica es parecida a la que practican contra nuestro pueblo en la calle»; «ellos saben que viven por su pueblo y que su pueblo vive por ellos»; «éste es un momento político de gran trascendencia, en el que lo que está en juego no son uno o varios programas electorales sino nuestra propia supervivencia como pueblo»; «de esta forma, el colectivo de presos y presas resitúa el elemento sobre el que pivota todo el conflicto actual y que no es otro que el derecho universal a la autodeterminación que le corresponde a todo pueblo»; «con su decisión el colectivo no sólo resitúa la situación sobre el concepto de autodeterminación sino que, frente al intento constante de instrumentalización política del colectivo para conseguir una salida falsa y artificiosa, manifiesta con la contundencia de una huelga de hambre que la amnsitía es la única salida política real a su propia situación y para lograr la paz que este país y ellos mismos anhelan». 
drirse las ideas para más adelante pudrirse las personas, como consecuencia de su llegada al poder». La corrupción consistía en anteponer los intereses personales a los generales. Ante tal situación había que «hacer frente a la sensación generalizada de corrupción porque es la carcoma que va degradando a toda la sociedad» ${ }^{202}$.

Sobre la participación parlamentaria de Herri Batasuna, Idígoras afirmó que se pensaba utilizar el voto en las Cámaras, no todos los días, pero sí cuando le interesase a la Coalición. "Vamos a ocupar todos nuestros escaños y utilizarlos sin cortapisas cuantas veces sea necesario». Ya verían, añadió, si acudirían más de tres veces, como parece que había ocurrido en la legislatura anterior. Y, usando una argumentación muy habitual, concluyó: "Yo conozco un montón de parlamentarios que no han ido ni siquiera tres veces en toda la legislatura a Madrid ${ }^{203}$.

\section{Cuestiones de Gobierno}

Un partido nacionalista, que oficia de tal, no necesita un programa, que vaya más allá de sus tesis nacionalistas, entre otras razones, porque la ideología nacionalista, que fundamentalmente es ideología de poder, necesita ocultar para sus fines de captación y movilización cualquier otra ideología, que pueda dividir la unidad del pueblo, la unidad de la nación, proclamada por el nacionalismo como unidad social total. De la misma manera, un partido nacionalista, en cuanto tal, no tiene nada que decir sobre cuestiones de gobierno, es decir, sobre la política como dirección real de una sociedad. Y esto es lo que ocurre con Herri Batasuna. Si se exceptúan dos intervenciones de Idígoras, sobre las que no me atrevo a decir si son interpretaciones personales o del Grupo político al que pertence, no hay nada más que la afirmación de que el modo de hacer política de Herri Batasuna se basa en «el trabajo colectivo, tomando como base las propuestas y aportaciones que parten de la iniciativa social»204. En estas dos cuestiones, el líder de HB rechazaba para su agrupación la estrategia del «cuanto peor, mejor» y parecía inclinarse sobre una victoria del PSOE en lugar del Partido Popular. Sus palabras fueron éstas: «Es difícil precisar. A priori, se puede decir que el PSOE tiene una experiencia, la de Argel. Ya se han sentado con ETA, lo cual le da una cierta ventaja. De la derecha española, no sé. Si nos tenemos que atener a lo que están diciendo en campaña, la verdad es que pocas esperanzas podemos

\footnotetext{
202 El Correo 28-V-93 (31).

203 El Correo 29-V-93 (35).

204 El Correo 1-VI-93 (35).
} 
tener. En primer lugar porque a la derecha española hay que echarle de comer aparte. No es homologable a cualquier derecha europea. Tiene un "pedigree" que yo no lo quiero para mí» ${ }^{205}$.

\section{B) Crítica de los Partidos Políticos}

Al Partido Nacionalista Vasco le correspondió un 46,40\% del apartado de censura. «Si quieres ser — dijo Idígoras en Anoeta- medio vasco o medio español, vota al PNV, que es quien más veces ha inclinado la cabeza ante Madrid» ${ }^{206}$. Todo cuanto se criticó se hizo desde tres claves: La ausencia, más bien renuncia, a un proyecto nacional vasco, en donde se encajaron las acusaciones de colaboracionismo y de proespañol; la utilización del apoyo al Estado español para acceder a las instituciones políticas y desde ellas construir un «peneuvismo» económico y social; y, por último, la responsabilidad de la crisis económica, que se hace desde el mito de la expropiación del País por el centralismo estatal y desde la voluntad de arruinar a Euskal Herria.

Todos los partidos importantes, entre ellos el PNV, eran culpables de la situación de bancarrota económica, en la que se encontraba el País Vasco. Al comienzo de la campaña se les decía que ocultarían a sus electores «el desvío de fondos de Euskadi al Estado: un billón de pesetas en los tres últimos años» ${ }^{207}$. Siendo auténticos «politiqueros» tanto los del PNV como los del PSOE, aquéllos, sin embargo, habían hecho de «monaguillo» del Partido Socialista en las reconversiones industriales realizadas en el País Vasco. Unos y otros querían «arruinar Euskal Herria» ${ }^{208}$.

El funcionamiento del PNV era como el de «la "cosa nostra" en su acción política e institucional». Todos los que no se sometían a sus intereses iban «a la hoguera de las discriminaciones», lo cual les desligitimaba para hablar de democracia. Los que, por otra parte, culpaban a HB de ser responsable de las escasas inversiones, que se realizaban en Guipúzcoa, carecían de «vergüenza, porque en Vizcaya, donde son la primera fuerza el índice de producción industrial ha bajado y en la margen izquierda la tasa de paro llega al $33 \%{ }^{209}$.

205 El Correo 29-V-93 (35). Opinión distinta manifestó Begoña Garmendia en Deia 26-V-93 (6), al decir: «Como vascos, no debemos caer en el juego de si va a ser mejor el PSOE o el PP». Sin embargo, Patxi Zabaleta afirmó que «por sensibilidad histórica los verdaderos militantes del PSOE deberían ser un sector social más dispuesto a entender nuestras reivindicaciones» (Deia 2-VI-93, 9).

206 Egin 30-V-93 (10).

207 El Correo 21-V-93 (30).

208 El Correo 3-VI-93 (32).

209 El Correo 23-V-93 (44). Ver, también, Egin 23-V-93 (6). 
Por todo ello se afirmaba que el voto al PNV, y también al PSOE, era «para el cierre de empresas» ${ }^{210}$.

El PNV era, además, reponsable de permitir la política de dispersión de los presos y de cerrar los ojos ante el problema. La invitación de Arzalluz hecha a la Mesa Nacional de HB para que secundase la huelga de hambre promovida por los presos de ETA fue respondida con estas palabras. «No sería la primera vez que los militantes de HB hemos hecho huelgas de hambre para denunciar la situación vivida por los presos» ${ }^{211}$.

Otro tema echado en cara al PNV y a su coaligado Partido Socialista, en íntima relación con la acusación de utilización de procedimientos mafiosos, fue el de la corrupción política y social. «El trabajo de los partidos convencionales — dijo Begoña Garmendia— se está convirtiendo en el control de los puestos de trabajo, tanto en la política como en la economía». Lo grave del tema era que semejantes comportamientos creaban la costumbre entre la gente de interpretar la política como la corrupción de las ideas y de las personas, una vez alcanzado el poder. O, dicho con otras palabras, el fin de la política era únicamente el poder; las ideas, el camino e instrumento para acceder a él, no para realizarlas desde el po$\operatorname{der}^{212}$. En el escenario de Anoeta, Idígoras, con modos mitineros vehementes, teniendo como telón de fondo las actuaciones del Consejero de Interior contra ETA, dijo: «Hace falta una limpieza a fondo y fumigar y limpiar las instituciones de delincuentes. Atutxa, comienza por limpiar tu casa, el PNV, de delincuentes y sinvergüenzas» ${ }^{213}$. Lo mismo dijo con otras palabras Gorostiaga, esta vez, refiriéndose a todos los Partidos Políticos y añadiendo una dosis de crítica a la democracia representativa, al afirmar que el voto era una buena inversión para el negocio de la política, ya que producía «buenas poltronas, enchufes, negocios, chanchullos, corrupción y miles de voluntades secuestradas para cuatro años, para vender al mejor postor los intereses de este pueblo» ${ }^{214}$.

Herri Batasuna consideraba que el pueblo vasco había optado claramente a favor del derecho de autodeterminación. No obstante, «los dirigentes de esos partidos que se autodenominan nacionalistas no están por la labor»; ni siquiera clarificaban su modelo de relaciones de Euskadi con el Estado ${ }^{215}$. Esta valoración de Jone Goirizelaia la corroboró Jon

210 El Correo 26-V-93 (29).

211 El Correo 27-V-93 (34).

212 El Correo 28-V-93 (31). Ver, también, 30-V-93 (41).

213 El Correo 30-V-93 (41).

214 El Correo 1-VI-93 (35). Ver Egin 26-V-93 (12), donde Idígoras pide la «desinfección» de las instituciones, y 21-V-93 (3), donde utiliza los términos de «mangantes» y «chorizos».

215 El Correo 29-V-93 (31). 
Idígoras, recurriendo, en parte, a argumentos manifiestamente falsos, cuando respondió así a la pregunta de si pensaba, como lo hacía Arzalluz, que ir a la autodeterminación en aquel momento sería como ir a la guerra: «Yo opino que no. En el caso de Euskadi no tenemos un problema de etnias que han generado históricamente unas fobias interraciales. El problema de Euskadi es mucho más simple, partiendo de que la situación de los Estados de cara a Europa no tiene razón de ser. Los Estados tienen que dar paso a representaciones de las naciones que los componen. Cuando Arzalluz habla de eso, lo hace porque él y su partido no están dispuestos a reclamar del Estado esa reivindicación. Si lo han hecho alguna vez, es como juego electoral y en este momento están agitando el fantasma del miedo, del pánico, de Yugoslavia» ${ }^{216}$. En lugar de política de autodeterminación, lo que defendía el PNV era «el vascongadismo» ${ }^{217}$, es decir, la ausencia de "proyecto nacional en Euskadi», porque, en definitiva, el PNV era «un partido proespañol que está colaborando directamente con todos los planes del Gobierno de Madrid» 218 .

Lo que en los últimos años había cambiado era «la mentalidad del PNV. Mediante el Pacto de Ajuria Enea pretenden liderar un movimiento de opinión con el que transmitir a la sociedad que entre el Estado y Euskadi no hay ningún contencioso y que el conflicto es entre vascos. Pretenden comunicar que hay un conflicto entre vascos buenos, que son los que aceptaron el Estatuto de Autonomía y vascos malos que somos los que no lo aceptamos. Es un planteamiento falso, programado por el Gobierno español y desarrollado por el PNV. Los jelkides necesitaban esa cobertura para limpiar su conciencia por la traición que han cometido contra la soberanía vasca. Ellos renunciaron a reclamar un proyecto nacional vasco y pactaron con el Estado un papel de gestor sumiso y bien pagado a cambio de hacer todo lo posible para combatir a los vascos que trataran de superar los límites que ellos aceptaron» ${ }^{219}$.

Joxe María Olarra, que participó en los actos de homenaje a los presos, militantes de ETA fallecidos y a sus familiares organizados en Rentería, dijo a Atutxa y Arzalluz que no se ilusionaran, porque el «proceso de lucha no está en saldo ni lo vamos a cambiar por un plato de lentejas» ${ }^{220}$.

En el tema de los presos de ETA, Arzalluz fue acusado de «hacer el trabajo sucio al Estado» ${ }^{221}$ y de defender la política de dispersión y de

\footnotetext{
216 El Correo 29-V-93 (35).

217 El Correo 2-VI-93 (29).

218 El Correo 5-VI-93 (25).

219 Egin 4-VI-93 (13).

220 El Correo 31-V-93 (26).

221 El Correo 1-VI-93 (35).
} 
reinserción, acusaciones comunes a todos los Partidos firmantes del Pacto de Ajuria Enea ${ }^{222}$.

Iruin interpretó que el crecimiento del PNV se debía «al voto español y conservador». Este apoyo suponía la hipoteca del PNV, que para seguir conservándolo se veía obligado a desarrollar «una política de sumisión muy clara a los intereses del Gobierno de Madrid». Una prueba de esto la daba el miedo «a dar pasos adelante en el diálogo político con ETA, si antes no lo autorizaba el señor Corcuera». El nerviosismo del PNV ante el ascenso del Partido Popular se debía a que tenía «miedo de perder el voto español y conservador». Iruin hacía suyas las palabras de Arzalluz de que los vascos no necesitaban al Estado: «Por supuesto que no, pero usted no suelta amarras ni las va a soltar, porque sus intereses de partido están ligados a ese Estado»223.

El 21,83\% de este apartado lo ocupó la crítica al Partido Socialista, que coincidió en buena parte con la realizada a otros Partidos Políticos y, especialmente, con la realizada al PNV, que no es necesario repetir.

Según HB no había diferencias substanciales entre el Partido Popular y el Partido Socialista. Ello explicaba que sus líderes estuviesen condenados a insultarse durante la campaña ${ }^{224}$ y que la alternancia, que se pretendía aparentar con la bipolarización, fuese absolutamente falsa ${ }^{225}$, porque la opción entre el PSOE y el PP era la opción entre «el sida y el cáncer» ${ }^{26}$. Partido centralista ${ }^{227}$ y máximo responsable de la crisis económica, el Partido Socialista utilizaría los votos para cerrar más empre$\operatorname{sas}^{228}$. En un afán de presentar al PSOE como antiobrero, principalmente con los que se mostraban laboralmente beligerantes (la crítica iba, también, contra el PNV), se dijo que la comarca de Ayala había sido «elegida como una zona de desindustrialización y un castigo para los trabajadores que tradicionalmente han tenido una posición de lucha contra los planes de los gobiernos central y vasco» 229 .

Sus planteamientos para conceder el indulto a Amedo lo deslegitimaban para hablar de paz, así como la «evidente falta de voluntad política» para atajar el tráfico de estupefacientes lo hacía culpable del problema de

${ }^{222}$ El Correo 29-V-93 (35). Ver en Egin 31-V-93 (16) las intervenciones en el homenaje a los presos.

223 El Correo 2-VI-93 (29).

224 El Correo 21-V-93 (30).

225 El Correo 24-V-93 (26).

226 El Correo 28-V-93 (31).

227 El Correo 22-V-93 (33).

228 El Correo 26-V-93 (29).

229 El Correo 26-V-93 (29). 
la droga. «No bastaba con poner a Garzón en las listas electorales, sino que hay que crear instrumentos de prevención» ${ }^{230}$.

Se le acusó, también, de utilizar a los GAL, a Amedo y a Ynestrillas para acabar con ETA en un contexto, en el que se identifica a ésta con Herri Batasuna ${ }^{231}$.

Se exigió, como si la cosa no estuviera claramente manifestada, al Partido Socialista, como también al PNV (aunque esto resultaba más problemático), que explicase definitiva y claramente su oposición al reconocimiento al País Vasco del derecho de autodeterminación ${ }^{232}$.

Del Partido Popular (12,15\% de este apartado) se criticó su colaboración a través de la UPN en el desvío de fondos de Euskadi al Estado; de ocultar los grandes problemas durante las elecciones por ausencia de diferencias importantes con el Partido Socialista; de ser culpable de la injusticia que sufre el pueblo vasco; de ser centralista, falsa alternativa y «cáncer» de la política; de no ser homologable con los demás partidos europeos conservadores y de corrupción ${ }^{233}$.

De Unidad Alavesa $(10,91 \%)$, además de dirigirle todas las críticas hechas a la derecha española y a los partidos del sistema en general, se dijo que había que tener cuidado, en concreto, en Alava con sus intentos de «ocultar la fuerza de HB mediante trucos y juegos sucios». La campaña en tal territorio histórico sería una confrontación entre «las fuerzas más reaccionarias de la derecha, representadas por UA y el proyecto abertzale y de izquierdas de Herri Batasuna» ${ }^{234}$.

Unidad Alavesa era «un mal sueño». Recordaba según Antón Morcillo «al pasado, a las noches negras del nazismo, a la quema de libros y satanización de lo vasco, al españolismo puro y duro de los tiempos del caudillo». UA se manifestaba contraria al euskera, «nuestra única lengua nacional». Según Morcillo, «sólo el alma vil y retorcida de los fascistas puede lograr regocijo en la desaparición cultural de los pueblos». Las elecciones en Alava era cosa de dos: Herri Batasuna o Unidad Alavesa. Los demás partidos habían quedado apartados de las mismas. Por eso cualquier desviación del voto hacia partidos como Euzko Alkartasuna era puramente «testimonial y una zancadilla al abertzalismo, porque el único beneficiario va a ser $\mathrm{UA} »^{235}$.

230 El Correo 27-V-93 (34).

231 El Correo 31-V-93 (26).

232 El Correo 29-V-93 (31).

233 Ver El Correo 21-V-93 (30); 22-V-93 (33); 23-V-93 (44); 24-V-93 (26); 28-V-93 (31); 29-V-93 (35); 1-VI-93 (35); 2-VI-93 (29); 4-VI-93 (31).

234 El Correo 23-V-93 (44).

235 El Correo 31-V-93 (26). 
Euzko Alkartasuna-EUE $(8,68 \%)$ tuvo el mismo modelo de censura que el Partido Nacionalista, si se exceptúa lo relativo a la gestión de Gobierno y a la coalición con el Partido Socialista, que no se dieron en este caso. En esencia, el rechazo y condena de esta agrupación se basó en la ausencia de un proyecto nacional vasco y su sustitución por el «provincianismo». Hablar de «nacionalismo constitucional», como lo hacía la coalición según Idígoras, era no decir absolutamente nada. Por eso, se le criticó su «indefinición política» y se le pidió que concretara sus posturas sobre el nacionalismo. Su presentación como la primera fuerza en Guipúzcoa era un mensaje «para animar a la clientela de un partido que se encuentra en situación de drama» ${ }^{236}$.

236 El Correo 5-VI-93 (25). Ver también El Correo 2-VI-93 (29). En Deia 5-Vl-93 (7) Idígoras califica a EA de «uniprovincialista». 